\title{
Sylvain Lévi
}

Professeur au Collège de France

(1863-1935)

\section{L'I nde et le Monde}

(1928)

Honoré Champion, Éditeur, Paris

\begin{abstract}
Un document produit en version numérique par Jean-Marc Simonet, bénévole.

Courriel : Lean-Marc_Simonet@uqac_ca
\end{abstract}

Dans le cadre de la collection: "Les classiques des sciences sociales"

Site web: http://www.uqac.ca/Classiques_des_sciences_sociales/

Une collection développée en collaboration avec la Bibliothèque

Paul-Émile-Boulet de l'Université du Québec à Chicoutimi

Site web: http://bibliotheque.uqac.ca/ 


\section{Politique d'utilisation de la bibliothèque des Classiques}

Toute reproduction et rediffusion de nos fichiers est interdite, même avec la mention de leur provenance, sans l'autorisation formelle, écrite, du fondateur des Classiques des sciences sociales, Jean-Marie Tremblay, sociologue.

Les fichiers des Classiques des sciences sociales ne peuvent sans autorisation formelle:

- être hébergés (en fichier ou page web, en totalité ou en partie) sur un serveur autre que celui des Classiques.

- servir de base de travail à un autre fichier modifié ensuite par tout autre moyen (couleur, police, mise en page, extraits, support, etc...),

Les fichiers (.html, .doc, .pdf., .rtf, .jpg, .gif) disponibles sur le site Les Classiques des sciences sociales sont la propriété des Classiques des sciences sociales, un organisme à but non lucratif composé exclusivement de bénévoles.

Ils sont disponibles pour une utilisation intellectuelle et personnelle et, en aucun cas, commerciale. Toute utilisation à des fins commerciales des fichiers sur ce site est strictement interdite et toute rediffusion est également strictement interdite.

\section{L'accès à notre travail est libre et gratuit à tous les utilisa- teurs. C'est notre mission.}

Jean-Marie Tremblay, sociologue

Fondateur et Président-directeur général,

LES CLASSIQUES DES SCIENCES SOCIALES. 
Cette édition électronique a été réalisée par Jean-Marc Simonet, bénévole, professeur des universités à la retraite, Paris.

Courriel : Jean-Marc_Simonet@uqac.ca.

À partir du livre de Sylvain Lévi, (1863-1935)

Indianiste, Professeur au Collège de France.

L'I nde et le Monde.

Librairie ancienne Honoré Champion, Librairie de la Société de I'Histoire de France, Paris, 1928. 175 pages.

Polices de caractères utilisées :

Pour le texte: Verdana, 12 points.

Édition électronique réalisée avec le traitement de textes Microsoft Word 2004 pour Macintosh. $11^{\prime \prime)}$

Mise en page sur papier format: LETTRE (US letter), 8.5" $\mathrm{x}$

Édition numérique réalisée le 8 juin 2008 à Chicoutimi, Ville de Saguenay, province de Québec, Canada. 
Sylvain Lévi, (1863-1935)

Indianiste, Professeur au Collège de France.

L'I nde et le Monde.

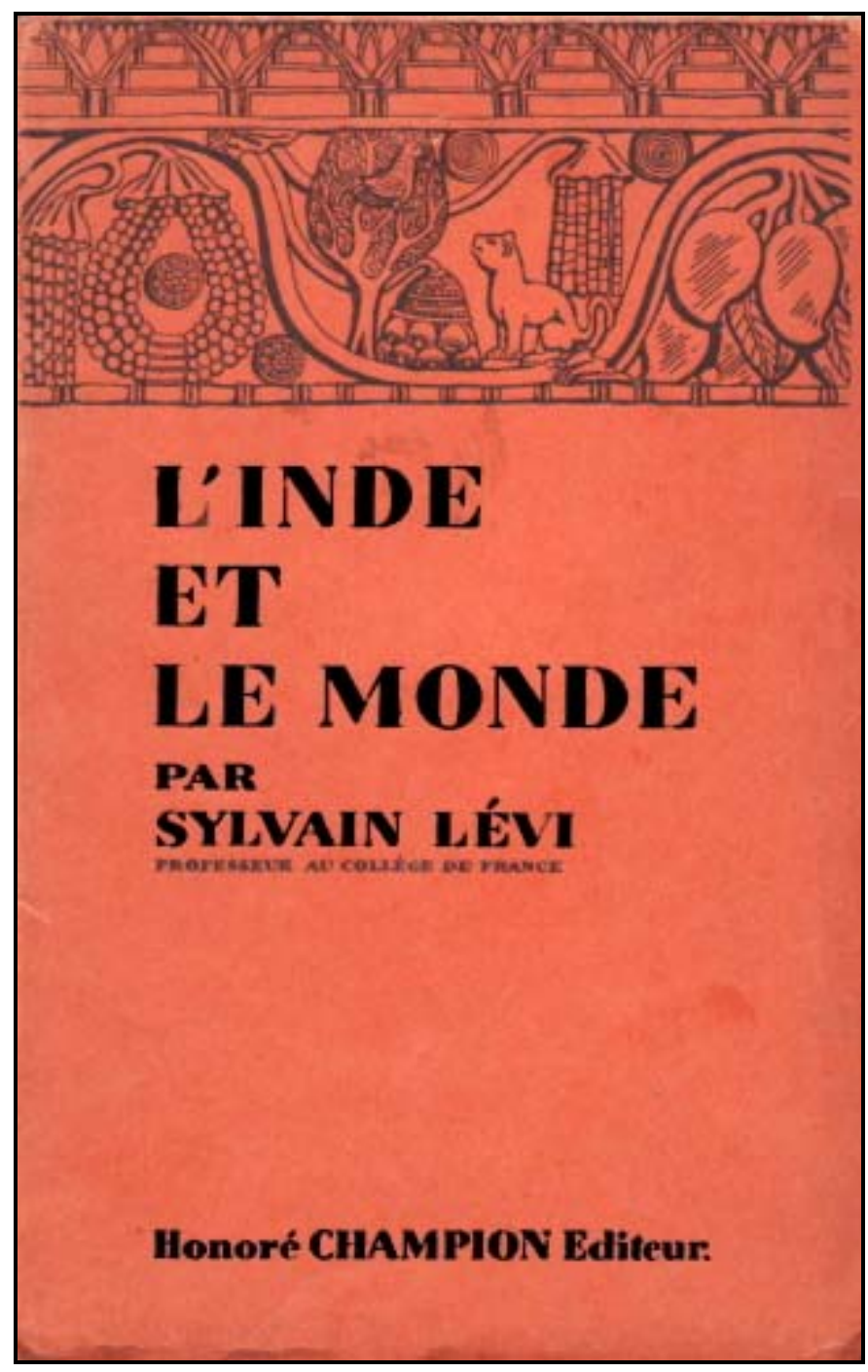

Librairie ancienne Honoré Champion, Librairie de la Société de I'Histoire de France, Paris, 1928. 175 pages. 


\section{Sommaire}

$\underline{\text { L'Inde et le Monde }}$

Humanisme bouddhique

Civilisation brahmanique

Civilisation bouddhique

Orient et Occident. Essai sur l'humanisme

Eastern humanism 


\section{L'Inde et le Monde}

$\underline{\text { Retour au Sommaire }}$

Un préjugé puéril que la science historique a battu en brèche dans l'Occident sans arriver à l'en expulser, mais que l'Orient continue à entretenir avec une sorte de piété, veut que chaque peuple soit, à ses propres yeux comme aux yeux du monde entier, l'auteur exclusif de sa propre civilisation et qu'il ne doive rien à l'étranger. Des esprits surannés, restés au stage d'un passé lointain, croient encore trop souvent que la barbarie commence aux frontières du pays natal. C'est ainsi qu'on voit, sur les anciennes cartes géographiques, à l'entour de la contrée spécialement figurée, un espace blanc, nu, vide de noms et d'indications. II semble que I'honneur national aurait à souffrir, s'il fallait reconnaître à des voisins la moindre part d'influence. L'amour de la patrie, comme l'amour de Dieu, peut dégénérer en fanatisme stupide; il faudrait, pour satisfaire les maniaques du chauvinisme, que tous les arts, toutes les sciences, toute les découvertes, toutes les inventions aient surgi du sol privilégié qui a eu I'honneur de les porter.

La réalité proteste contre cette conception puérile : la civilisation est une œuvre collective où chacun travaille pour l'avantage de tous. Sans remonter trop haut dans ces annales du passé que notre temps s'applique à déchiffrer, jetons les yeux sur la Grèce, bienfaitrice du monde, dispensatrice de beauté, de sagesse, et de vérité. II n'est pas un peuple, sur toute l'étendue de la terre, qui ne soit aujourd'hui son débiteur. Mais à quoi n'avait-elle pas elle-même emprunté ? Elle avait, de son propre aveu, reçu l'écriture des Phéniciens, la philosophie des Égyptiens; mieux instruits qu'elle de son propre passé, nous atteignons maintenant au-dessous de la Grèce classique une civilisation "égéenne » tout imprégnée d'influences orientales. La génération spon- 
tanée, chassée des sciences biologiques par les expériences de Pasteur, n'a point à espérer de refuge dans I'histoire. Qu'on ne vienne pas alléguer, en manière de réfutation, l'incertitude des périodes lointaines; les temps plus rapprochés n'en laissent apparaître que plus clairement la même vérité. II suffit de rappeler I'histoire de notre littérature; au XVI ${ }^{\mathrm{e}}$ siècle c'est l'étude des modèles grecs et latins qui suscite les chefs-d'œuvre de la Renaissance ; bientôt après l'I talie impose son goût subtil et maniéré ; l'Espagne triomphe ensuite dans l'œuvre de Corneille ; Racine associe dans la même dévotion Euripide et la Bible. $L^{\prime}$ Angleterre, mère des libertés politiques, préside à notre $X \mathrm{XVII}^{\mathrm{e}}$ siècle; après la Révolution, l'Allemagne romantique lui succède. Et tout récemment encore le théâtre scandinave, le roman russe ont marqué leur empreinte sur l'esprit français.

Est-ce à dire qu'il n'existe pas de génie national ? Tant s'en faut! C'est dans cette œuvre d'absorption qu'il manifeste au contraire toute sa puissance. Qu'est-ce, en effet, que le génie national si ce n'est la fusion harmonieuse des goûts et des tendances répartis, entre les groupes divers dont l'ensemble forme la nation ? Pour qu'une nation existe, il ne suffit pas de juxtaposer des territoires et de les soumettre à l'unique autorité d'un maître commun. Un conquérant brutal peut par de tels moyens fonder un empire ; son œuvre éphémère disparaît avec lui. Pour qu'une multitude d'hommes se soude dans cette unité supérieure qui constitue une nation, il faut qu'elle ait pris conscience, par les triomphes et par les deuils, d'une raison d'être intime qui totalise ses expériences ses espérances, ses aspirations. II ne s'agit pas là d'une entité mystique, mais d'une donnée de fait Entre tous les groupements de hasard qu'a tentés le caprice de I'histoire, la conscience nationale n'a retenu que les unions sincères, normales, et profondes. Les arrachements temporaires dus à la violence ne font que surexciter par l'épreuve de la douleur un sentiment net et précis d'unité nationale ; le pays mutilé se sent atteint dans l'équilibre nécessaire de ses forces vives. Dans l'intérieur d'un organisme puissamment constitué, un esprit commun ne tarde pas à se dégager par le jeu même de la vie. A l'occasion des doctrines ou des œuvres soumises à l'appréciation de l'opinion publique, les accords et les désaccords qui se manifestent laissent apparaître un résidu de préférences collectives, qui s'affirment définitivement dans un choix d'œuvres ou d'idées consacrées désormais comme « classiques». 
La fonction du génie national est donc essentiellement critique; la création reste toujours le privilège d'individualités exceptionnellement douées. Encore faut-il reconnaître que la société exerce même dans ce domaine une part d'influence, puisque ses préférences manifestées tendent à enfermer dans un cadre préalable l'invention créatrice. Dès lors, l'antinomie qu'on essayait de poser entre le génie national et les apports étrangers s'évanouit. Dans le perpétuel mouvement d'échanges qui met constamment en circulation tous les produits de l'activité humaine, le génie national choisit avec la sûreté de l'expérience acquise la part qu'il croit utile de s'assimiler, et il élimine le reste. II enrichit son propre fonds sans s'altérer, aussi longtemps du moins qu'il reste maître d'agir à son goût; lié à l'existence de la nation, il est condamné à disparaître avec la nation qui s'exprimait en lui. La Grèce conquise avait pu, suivant la célèbre formule du poète Horace, « conquérir son farouche vainqueur » ; le génie grec ne survécut pas longtemps à l'indépendance de la Grèce. Mais si sa force de production était évanouie sa puissance de fécondation se perpétuait, pour ainsi dire, jusque dans son cadavre; retrouvé par l'Occident chrétien après des siècles d'oubli, il lui donnait la Renaissance et changeait le cours de I'histoire.

L'Inde pourtant, à l'en croire, semble avoir échappé à la loi commune. Ses traditions, consignées dans l'immense littérature des brahmanes, ne savent rien de précis sur le monde environnant ; la nature même paraît s'être plu à tracer autour d'elle une frontière d'isolement splendide. Une ligne ininterrompue de montagnes colossales barre le passage au nord; à l'est et à l'ouest, ses côtes inhospitalières baignent dans un Océan périlleux ; entre la mer et la montagne, un désert de sables mouvants défend le seuil resté ouvert le long de l'Indus. On dirait qu'une divinité malicieuse a voulu tenter ici dans des conditions idéalement favorables, une expérience d'humanité en vase clos. La société elle-même s'est appliquée de son côté à seconder l'œuvre de la nature; il serait difficile de retrouver ailleurs un système d'institutions qui tende aussi résolument à exclure l'étranger. Je n'ai pas besoin d'insister ici sur l'originalité du système des castes; on peut vanter les services qu'il a rendus à I'Inde ou critiquer ses graves inconvénients; quelque opinion qu'on professe, il faut reconnaître qu'en principe il érige autour de l'Inde une barrière infranchissable. Ailleurs, on peut aspirer au droit de cité, à la naturalisation ; ici, il faut se résigner à rester éternellement 
au dehors, si le hasard de la naissance ne vous a pas ouvert automatiquement la porte.

Ces conditions singulières, en combinant leur efficacité, ont créé un amalgame humain d'un type unique, qu'on hésite à définir. L'Inde n'est pas une unité ethnique, aucun peuple ne trahit aussi nettement l'extraordinaire diversité de ses origines. L'Inde n'est pas une unité linguistique ; les parlers y sont encore beaucoup plus nombreux que les races. L'Inde n'est pas pourtant une pure expression géographique, vide de valeur humaine, déterminée seulement par des accidents du sol, soit reliefs, soit dépressions. Personne ne conteste qu'il existe une civilisation indienne, caractérisée par la prédominance d'un idéal, d'une doctrine, d'une langue, d'une littérature et d'une classe. De I'Himalaya jusqu'à Ceylan, les esprits cultivés et les âmes simples acceptent la même loi transcendante (dharma) liée à l'éternité des transmigrations (samsâra) et à la rétribution inévitable des actes à travers la série des existences (karman). Religions et philosophies s'accordent à prêcher le néant de l'individu, la vanité illusoire des choses. Le sanscrit, langue des dieux, jouit encore d'un prestige deux ou trois fois millénaire. Vyâsa, Vâlmîki, Kâlidâsa sont reconnus unanimement comme des modèles de goût, de poésie, de style. Le brahmane est partout vénéré comme une sorte de divinité terrestre.

Mais, I'Inde en est la preuve, une civilisation ne suffit pas pour faire une nation. La comparaison avec les grands peuples classiques montre trop clairement ce qui manque à l'Inde. Et quand je parle de I'Inde, je n'entends parler que de l'Inde ancienne; je refuse résolument de me mêler aux polémiques et aux passions de l'heure présente. La science qui veut rester fidèle au culte sincère de la vérité doit se maintenir dans ces hauteurs sereines, «templa serena », que vantait le poète latin, ou pour emprunter le langage du bouddhisme, dans le «plan des lois » (dharmadhâtu) où les phénomènes en quelque sorte sublimés perdent la puissance de souillure et de trouble qui leur était naturellement inhérente. Qu'on se rappelle l'admirable scène de Sakountalâ où le roi Doushyanta redescend du paradis, en compagnie de Mâtali, dans le char d'Indra. II frémit encore du combat qu'il vient de soutenir contre les Asuras démoniaques; son cœur palpite encore au souvenir de l'épouse bien-aimée qu'il a répudiée dans un moment d'oubli ; le tumulte des passions gronde, mal comprimé, au plus profond de son âme. Mais le char 
aérien approche de l'ermitage sacré où l'ascète Kasyapa pratique et enseigne la sagesse; et soudain le roi se sent gagné par un apaisement inconnu. II est digne alors de pénétrer dans l'asile des sages, où la destinée lui ménage encore une faveur suprême.

Et nous aussi, au seuil du domaine où règne la science radieuse, nous devons oublier les vaines agitations, si nous voulons nous rendre dignes de contempler au moins quelques lueurs de la vérité. J'ai dit que l'Inde, unie dans une civilisation commune, n'avait pourtant pas formé une nation. Il a manqué à ce corps immense la hiérarchie des fonctions qui, dans les organismes supérieurs, règle, contrôle et distribue les mouvements de la vie. La nation a, comme les individus, un cœur et un cerveau où convergent et d'où rayonnent en perpétuels échanges les activités collectives. Rien d'essentiel ne s'accomplit sans leur intermédiaire ; les accidents les plus lointains s'y enregistrent et réagissent sur eux ; les secousses qui les ébranlent compromettent la vigueur et la durée de l'ensemble. La Grèce morcelée en cités innombrables, dispersée comme en fragments à travers l'étendue des mers, depuis le littoral asiatique jusqu'à la Sicile, s'ordonne autour d'Athènes. Supprimez Athènes, et I'histoire grecque n'est plus que de la poussière. L'Empire Romain, qui va de l'Atlantique à l'Euphrate, se confond pourtant avec sa capitale ; le dernier poète du latin classique, Rutilius Numatianus, résumait dans une formule saisissante l'œuvre de Rome : « Avant c'était le monde ; et toi, tu en as fait la Ville »,

Urbem fecisti qui prius orbis erat.

II serait oiseux de marquer ici ce qu'est Londres pour la nation britannique, Paris pour la nation française. En face de ces noms pour ainsi dire synthétiques, où faut-il chercher le centre de I'Inde ? Est-ce à Bénarès, foyer intense d'activité religieuse, mais qui n'a joué aucun rôle dans vie politique du pays ? à Pâtaliputra, à Kanyâkubjâ, à Ujjayinî, à Pushkaiâvatî, à Pratishthâna, à Kânchi, dans tant de capitales qui brillèrent d'une splendeur éphémère pour s'abîmer ensuite dans une banale médiocrité ? Comme des feux follets qui s'allument et s'éteignent au hasard dans le silence de la vaste nuit, elles se sont évanouies avant d'avoir arrêté le regard d'un chroniqueur. 
Et c'est là que se trahit plus cruellement encore, l'incohérence douloureuse de cette masse immense. L'Inde n'a pas d'histoire. Une nation, comme une famille, a ses archives, où elle dépose et surveille précieusement les titres de noblesse qui sont I'honneur de son passé et la garantie de son avenir. Elle a ses annales qui affirment, au-desssus des générations passagères, la continuité consciente de la tâche collective. Elle a ses grands hommes, en qui elle se plaît à incarner son idéal ; elle les vénère comme ses guides et ses protecteurs sur la voie énigmatique du temps; elle défend jalousement leur mémoire contre les menaces de l'oubli ; elle recueille, comme des reliques précieuses, même les moindres indices qui précisent leur souvenir. L'Inde a bien sauvé quelques grands noms de son passé religieux ou littéraire : mais elle n'a préservé ces noms qu'en les noyant dans la brume du rêve ou dans les fantaisies contradictoires de la fiction. Elle a eu un Sankara, grand peut-être comme un François d'Assise et comme un Luther. Qu'en a-t-elle fait ? Un héros de miracles vulgaires et de tournois scolastiques, si pâle, si incolore, si flou, si dénué de réalité qu'elle le promène à volonté des millénaires qui précèdent le Christ jusqu'au premier millénaire de l'ère chrétienne. Pas un nom, pas un fait pour fixer exactement sa place dans la suite des siècles. Et pourtant il s'agit d'une personnalité hors ligne qui marque une des phases décisives de la pensée humaine et qui survit encore profondément empreinte dans l'âme de I'Inde actuelle! L'Inde a eu un Kâlidâsa, poète exquis, créateur ingénieux de formes et d'images, interprète harmonieux les plus nobles émotions. Qu'en a-t-elle fait ? Un héros de bons mots et de mauvais tours qu'elle installe avec indifférence soit à la cour d'un roi Vikramâditya qu'elle relègue au I $^{\text {er }}$ siècle avant l'ère chrétienne, soit à la cour du roi Bhoja, qui règne dix siècles plus tard. En revanche, elle multiplie les détails les plus copieux sur les Pândavas, sur Râma, sur les innombrables figures de sa légende épique, qu'elle pourrait à juste titre s'enorgueillir d'avoir créées, car elle en a fait les dépositaires d'un magnifique idéal ; mais prise aux séductions de ses propres rêves, elle a pour s'y abandonner préféré fuir les spectacles moins complaisants de la réalité.

Et, par une anomalie sans exemple dans le reste de I'humanité, c'est par les enseignements de l'étranger qu'elle a commencé à connaître sa véritable grandeur. Le plus grand de ses fils, le Bouddha, elle l'avait oublié. Tandis que le Tibet, la Chine, la Corée, le Japon, l'Indochine répétaient pieusement la 
biographie du maître, les yeux tournés vers son berceau, I'Inde qui lui avait donné le jour ne savait plus rien de lui. En vain le Népal gardait dans sa vallée les originaux sanscrits des textes sacrés; en vain Ceylan préservait avec une fidélité plus que deux fois millénaire, malgré les révolutions, les invasions, les conquêtes, le trésor des Trois Corbeilles bouddhiques rédigé dans un dialecte indien, le pali, le frère cadet du sanscrit; le nom du Bouddha, voué d'abord à l'exécration par le brahmanisme triomphant, avait bientôt disparu dans l'universelle indifférence, sans provoquer une seule fois un effort de sympathie ou de curiosité. C'est l'Europe qui a rendu le Bouddha à I'Inde. Par ses voyageurs, par ses missionnaires, par ses savants, l'Europe avait retrouvé du plateau tibétain au littoral du Pacifique les traces éclatantes de l'activité bouddhique ; elle voulut en savoir davantage: Hodgson et Burnouf donnèrent à la science, I'un les matériaux, l'autre les faits. Et l'Inde stupéfaite connut, par l'admiration du monde, la grandeur du fils qu'elle avait dédaigné. Parmi les rois de l'Inde, il en est un qui éclipse même les plus glorieux; c'est Asoka le Maurya. Maître d'un puissant empire fondé par son aïeul, étendu par ses armes, et qui couvrait l'Inde entière, il s'était assigné la tâche de pratiquer et de propager le bien ; ses édits gravés sur des roches et sur des piliers dans toutes les provinces soumises à son autorité, prêchent dans un langage simple et familier les plus hautes leçons de bonté, de douceur, de charité, de respect mutuel que l'humanité ait jamais entendues. Mais, durant de longs siècles, les caractères n'en étaient plus que des lettres mortes; il a fallu un Prinsep pour arracher leur secret aux pierres devenues muettes et pour ressusciter cette période splendide où la politique hindoue, encouragée et soutenue par une foi agissante, prétendait rayonner jusqu'à la Cyrénaïque et jusqu'à l'Épire, sur les confins du monde romain et du monde carthaginois. Dans le foisonnement de la littérature sanscrite, I'Inde a enfanté un génie exceptionnel, né pour toutes les initiatives et pour toutes les audaces, Asvaghosha ; il est au point de départ de tous les grands courants qui ont renouvelé et transformé I'Inde vers le début de l'ère chrétienne. Poète, musicien, prédicateur, moraliste, philosophe, auteur dramatique, conteur, partout il invente et partout il excelle ; il évoque dans sa richesse et sa variété Milton, Gœthe, Kant et Voltaire. Mais Asvaghosha, il y a trente ans, n'avait pas même une simple mention dans I'histoire littéraire de I'Inde; Asvaghosha est tout entier une conquête de l'érudition occidentale. II est superflu d'allonger cette liste; elle laisse entrevoir assez ce que 
I'Inde doit, dans l'éveil de sa conscience, à son contact avec l'Europe. Elle montre - aux dépens de l'Inde, il est vrai - à quels périls s'expose un peuple qui prétend s'isoler en dehors des mouvements de la civilisation universelle.

Mais l'Inde a-t-elle jamais réalisé vraiment cette conception farouche? Depuis les invasions de Mahmoud le Ghaznévide, après I'an 1000 de J.-C., les faits ne répondent que trop clairement. Offerte en proie à toutes les convoitises, disputée par toutes les rivalités, elle est soudée à I'histoire de I'I slam et aux destinées de l'Europe. Et si nous remontons jusqu'au passé le plus lointain, le mirage de l'isolement s'évanouit encore à la lumière des faits. Le premier rayon qui vient éclairer le seuil de I'histoire indienne jaillit d'un texte cunéiforme découvert dans le voisinage de l'Arménie. Les documents de la Babylonie et ceux de la Perse nous aident ensuite à percer de quelques lueurs l'obscurité compacte des siècles éloignés. Puis la Grèce surgit et son génie radieux semble éveiller définitivement le monde; sans elle, I'histoire de l'Inde ne serait encore qu'énigme et confusion ; par elle, l'ordre et la précision s'introduisent dans I'histoire de l'I nde. L'identité, reconnue par William Jones, du Chandragupta indien et du Sandrocottos nommé par les historiens d'Alexandre, reste la pierre angulaire de toute la chronologie. Pendant un millier d'années, I'histoire de l'Inde est en grande partie I'histoire des connaissances grecques sur l'Inde. Ce contact prolongé pose le problème des influences réciproques, qui met en jeu l'originalité même du génie indien. Aux environs de l'ère chrétienne, la Chine à son tour entre en rapports avec l'Inde, et pendant un millénaire, le zèle religieux, la politique, le commerce rapprochent ces deux pays. Les échanges suivent une double voie la route de terre qui contourne ou traverse le massif du Pamir et d'oasis en oasis franchit les déserts sablonneux du Turkestan ; la voie de mer qui par I'Insulinde relie les ports indiens aux ports chinois. La rencontre des deux grandes civilisations produit de part et d'autre un amalgame étrange ; d'un côté, la "Sérinde », comme disaient les Grecs au temps de l'empereur Justinien, de l'autre côté l'Indochine, comme nous disons aujourd'hui, désignations équivalentes qui marquent bien toutes deux la zone d'équilibre instable entre deux tendances, deux langues, deux sociétés rivales. Dans ce conflit dissimulé, I'Inde paraît triompher assez longtemps. Les explorations récentes de l'Asie Centrale ont révélé une annexe inattendue du monde indien; un peu plus tôt, mais aussi à une date récente, l'étude des monuments et des inscrip- 
tions a montré dans l'Indochine et dans l'Insulinde des colonies hindoues fidèles aux arts, aux religions, aux œuvres littéraires de I'Inde. Enfin au vue siècle, le bouddhisme indien conquiert encore un nouveau champ d'expansion pour la culture indienne : sur les hauts plateaux du Tibet, une population rude et barbare voit s'élever des monastères où des missionnaires zélés traduisent du sanscrit la masse énorme des textes canoniques. Ainsi, de la Méditerranée à l'Océan Pacifique, les nations proches et lointaines viennent s'ordonner autour de l'Inde et projeter un faisceau convergent de rayons sur la nuit muette de son passé. L'image qui s'en dégage n'est pas à coup sûr nette et complète à souhait; trop souvent les documents se taisent ou s'interrompent au moment même où la curiosité se fait plus pressante ; trop souvent aussi, les parcelles éclairées accusent de menus détails qui risquent par leur insignifiance apparente de fatiguer ou de décourager l'attention.

Incomplet, fragmentaire, coupé de graves lacunes, le tableau tel qu'il est, suffit à montrer la vraie grandeur de I'Inde, sa grandeur humaine, plus belle que les rêves étroits de la vanité. Dans cet immense mouvement d'échanges qui constitue de temps immémorial la vie organique de l'espèce humaine, l'Inde a largement donné comme elle a largement reçu. On peut, au gré des passions, exalter ou déprécier son rôle; mais son rôle, elle l'a joué comme le reste du monde, avec le reste du monde. Si la nature et les lois ensemble ont tout fait pour l'isoler, son cas n'en prend qu'une valeur plus décisive: chaque groupe, race ou nation est dans ses actes comme dans sa pensée, dans sa conscience comme dans ses instincts, solidaire de toute l'espèce humaine. 


\section{Humanisme bouddhique}

Si l'histoire était une simple collection de faits classés dans un ordre de succession chronologique, elle aurait déjà le droit d'être admise dans le cycle régulier des sciences. La science est, en effet, la connaissance des rapports que l'intelligence humaine découvre ou établit dans la masse en apparence désordonnée des phénomènes étudiés. Les phénomènes de la matière, c'està-dire ceux qui nous apparaissent comme extérieurs et irréductibles à notre conscience, se laissent ramener plus aisément à des lois, c'est-à-dire à des rapports permanents, constants, immuables; les sciences qui en traitent y prennent une apparence de rigueur qui leur vaut, dans l'usage courant, la désignation de « sciences » par excellence. Mais l'histoire, elle, traite de phénomènes d'ordre humain, c'est-à-dire d'un ordre qui nous est directement et intimement accessible; par notre conscience propre, nous connaissons la complexité illimitée des faits humains ; nous sommes d'avance prévenus contre les abstractions simplistes qui, en retenant seulement un nombre restreint de facteurs, prétendent introduire dans l'histoire des lois impératives. En fait, l'apparente infériorité de l'histoire tient justement à sa valeur spéciale de double réalité, subjective et objective à la fois. En rétablissant entre des phénomènes isolés des rapports de succession chronologique, elle superpose à ces faits une explication qui les ramène aux lois générales de la causalité ; dès qu'un fait suit un autre dans l'ordre du temps, elle admet que le second est la résultante du premier, et l'effort de l'esprit doit s'appliquer à faire, apparaître leur connexion intime. Ces connexions sont de deux sortes, car elles se produisent non seulement dans le temps, mais aussi dans l'espace; simultanés dans le temps, mais séparés dans l'espace, les faits constituent des synchronismes; séparés dans le temps, indépendamment 
de leur situation dans l'espace, ils constituent des successions. Si les sciences s'accroissent en dignité selon que des phénomènes de plus en plus nombreux s'y organisent dans des relations de plus en plus simples, l'histoire a d'autant plus le droit d'être comptée dans les sciences qu'elle embrasse dans un même rapport de connexion des faits de plus en plus étendus dans les domaines du temps et de l'espace.

En attendant une histoire universelle de l'humanité qui s'élabore lentement, mais qui est encore bien éloignée de son achèvement, il a fallu chercher, dans la multitude des faits, des centres provisoires de convergence par rapport auxquels on pourrait ordonner l'ensemble de la matière historique, telle qu'elle se présente à la considérer d'un lieu déterminé de l'espace. Les grandes religions du type universel semblent particulièrement propres à tenir ce rôle leur ambition consciente et avouée les porte à élargir leur horizon au delà des frontières ethniques, linguistiques, ou politiques; elles travaillent à créer un lien profond et durable entre des groupes de toutes provenances, en leur proposant un idéal commun dont ils sont tous solidaires pour le réaliser dans l'avenir, et dans le passé une tradition commune exprimée par l'histoire d'une communauté privilégiée. II semble que chaque religion du type universel crée et développe une civilisation, sinon universelle, du moins internationale ; en réalité, elle ne fait plutôt que dégager des traits généraux qui demeuraient encore latents ou inconscients, mais qui n'en existaient pas moins en puissance dans l'intérieur de groupements divers qui n'avaient pas encore reconnu de cohésion entre eux. En se superposant aux autres distinctions, la religion les efface si peu qu'elle en arrive bientôt à subir elle-même leur empreinte : le christianisme de l'Espagne, par exemple, est par certains aspects identique au christianisme de l'Angleterre; l'un et l'autre diffèrent pourtant entre eux autant que l'Angleterre diffère de l'Espagne. Plus une religion se propage, plus elle s'éloigne de son berceau, plus elle doit se modifier pour s'accommoder aux habitudes de ses nouveaux adeptes. Quand les différences spécifiques sont trop graves pour qu'elles puissent se concilier avec les données fondamentales d'une croyance nouvelle, la propagande est condamnée à échouer. Le christianisme comme religion d'État n'a jamais pu dépasser à l'est l'Asie Mineure d'où il est originaire; I'Islam n'a jamais pu entamer l'Europe que par accident; le Bouddhisme en tant que religion officielle n'a jamais pu atteindre le Tigre et l'Euphrate vers 
l'ouest. Un bloc religieux est donc bien une unité réelle, solide, intégrale, un système organique de civilisation.

Notre conception de I'histoire en Occident procède avec raison de ce principe. Elle place au centre la civilisation chrétienne qui est véritablement la civilisation de l'Occident ; c'est par rapport à cette civilisation qu'elle dispose les plans et les perspectives de I'histoire humaine. Rome occupe la place d'honneur; siège de la papauté, elle atteste que l'Église est l'héritière de l'empire romain ; la langue latine, maintenue et consacrée par l'Église, témoigne aussi de cette continuité. L'histoire romaine est donc comme une introduction nécessaire à l'histoire de la civilisation occidentale. Mais la civilisation romaine dérive en grande partie de la civilisation grecque; I'histoire de la Grèce vient donc se souder, comme une annexe indispensable, à l'histoire de Rome. D'autre part, le christianisme a, par Jésus et les Apôtres, son berceau en Palestine; le Nouveau Testament remplace, sans l'annuler, l'Ancien Testament, qui est le trésor de la civilisation juive. L'histoire du peuple juif vient à titre d'histoire « sainte » se placer au même rang que la Grèce et Rome. Autour de ces trois foyers, Rome, Athènes, Jérusalem, s'ordonnent les autres nations que les vicissitudes du sort ont tour à tour mêlées à leur histoire: Assyrie, Chaldée, Perse, Égypte, Carthage, Gaule, Espagne, Germanie, etc. Après la défaite définitive du paganisme romain, l'Europe nouvelle se forme par l'entrée graduelle des États nouveaux dans le giron de l'église chrétienne. La naissance et la diffusion rapide de l'I slam dressent en face du christianisme un champion redoutable ; durant plusieurs siècles, les deux adversaires se heurtent sans triompher l'un de l'autre. L'Église préside aux batailles, comme elle préside aux arts, à la littérature, à la vie sociale, à la politique. II semble que le monde entier vit dans l'Église et par l'Église. La Renaissance, d'abord favorisée par les papes, aboutit à la Réforme; dangereuse pour l'église catholique, la Réforme maintient le christianisme au centre des activités, tandis que la découverte de l'Amérique double les ressources et le domaine de l'Église chrétienne. II est superflu de pousser plus loin cette esquisse du rôle que le christianisme occupe dans la civilisation de l'Occident; les détails en sont familiers à tous les esprits, du moins en Occident. Si la civilisation de I'Islam a été moins féconde que la civilisation chrétienne, elle a cependant créé, elle aussi, un bloc homogène qui ne manque ni de grandeur ni de variété. Elle a, elle aussi, ses arts, ses littératures, ses sciences, qui ont fleuri sur un immense territoire, de- 
puis l'extrême ouest du continent africain jusqu'à l'extrémité orientale de l'Asie et la mer de Chine. Le pèlerinage de la Mecque, imposé ou tout au moins recommandé aux fidèles, affirme à travers les siècles et les distances, la cohésion de cet ensemble disparate ; des légions de pèlerins, orientés vers la cité sainte du Prophète, entretiennent sur toute l'étendue de la terre musulmane ces échanges de tout ordre qui assurent la vie et la durée d'une civilisation.

L'Extrême-Orient, dans son ensemble, n'appartient ni à la civilisation chrétienne, ni à la civilisation musulmane. Jésus et Mahomet peuvent y compter des fidèles, et même nombreux ; l'Église et l'Islam peuvent à l'occasion y jouer un rôle, et même important; le passé n'y relève point d'eux. Séparés des deux blocs de civilisation plus occidentaux, les peuples de l'ExtrêmeOrient n'ont-ils pas une unité qui les relie entre eux ? - L'usage qui les groupe sous le même vocable de géographie n'est-il qu'une fantaisie heureuse, ou ne traduit-il pas plutôt une impression d'unité sortie spontanément de l'observation des mœurs ? Ma réponse, s'il m'est permis d'en apporter une, ne sera pas douteuse, ou indécise : il existe une civilisation bouddhique, comme il existe une civilisation chrétienne et musulmane, et cette civilisation bouddhique couvre en étendue et en importance un domaine qui l'égale aux deux autres. Je voudrais tracer ici un programme d'étude de la civilisation bouddhique pour en montrer la richesse et la complexité infinies, et pour montrer aussi comment cette étude peut servir de foyer à un nouvel humanisme, l'humanisme asiatique, qui viendrait heureusement compléter et parfaire notre humanisme européen.

Le bouddhisme est d'origine indienne. La tradition est unanime pour placer le berceau du Bouddha sur la frange méridionale des monts Himalaya, au nord de la ville actuelle de Patna. Mais, sur la date de la Nativité et du Nirvâna, les opinions varient, dans l'Église aussi bien que chez les savants de notre époque. Qu'on se représente l'état de confusion où en seraient les recherches sur les origines du christianisme, sur les origines de I'Islam, s'il fallait hésiter, et avec un battement de plusieurs siècles, sur la date de Jésus ou celle de Mahomet. Le problème de la date du Bouddha pose le problème général de la chronologie de I'Inde ancienne; on sait qu'il n'est pas, dans l'histoire des peuples civilisés, d'énigme plus désespérée. On voudrait situer le Bouddha, et l'atmosphère autour de lui est envahie par un 
brouillard opaque. Si le problème reste insoluble, et peut-être il doit le rester à jamais, l'historien du bouddhisme ne peut se dérober au devoir d'examiner les traditions, les légendes que I'Inde est toujours prête à fournir en abondance, et de discuter les combinaisons hypothétiques proposées par les chercheurs modernes. Le problème des origines philosophiques de la doctrine enseignée par le Bouddha pose sous un nouvel aspect la question des rapports à établir entre le bouddhisme primitif et les écoles antérieures ou contemporaines du Maître. Les analogies de pensée, de méthode, de style saisissables à première vue dans les Upanishad du type archaïque d'une part, d'autre part les controverses engagées fréquemment par le Bouddha au sujet des rites védiques, de leur valeur et de leur signification, imposent l'obligation d'étudier l'ensemble de la littérature du Véda comme l'introduction nécessaire aux recherches sur les origines bouddhiques.

A côté du Bouddha, parallèlement à lui, sur le même terrain, auprès des mêmes princes et des mêmes populations, un des maîtres d'hérésie que le Bouddha trouve constamment dressés contre lui, Mahâvîra, réussit à fonder une église durable qui s'est perpétuée jusqu'à notre temps et qui a conservé un trésor de textes antiques; c'est la religion du Jina, le Jaïnisme. L'historien du Bouddhisme dispose là d'un terme de comparaison et d'un moyen de contrôle qu'on est surpris de voir trop souvent négligés ou ignorés. Le contraste entre les destinées des deux églises, qu'on peut appeler des églises jumelles, sollicite la réflexion; toutes deux prétendent s'adresser à tous sans distinction d'origine, de classe, de race; en fait, l'une poursuit encore, dans son pays d'origine, une existence médiocre et terne dans un cercle étroit de riches marchands et de moines pour la plupart ignorants où elle est restée presque toujours confinée; l'autre a connu la fortune éclatante, a dominé l'Inde entière, a conquis toute l'Asie Orientale, compte encore ses fidèles par centaines de millions, mais a disparu depuis dix siècles du sol qui l'avait produite.

II serait facile de montrer que, de la même façon, tous les problèmes généraux de l'antiquité indienne viennent se grouper tout naturellement autour de l'étude du bouddhisme: ainsi le premier Concile tenu à Râjagriha immédiatement après le Nirvâna et qui passe pour avoir donné la première édition de la Bible bouddhique (Tripitaka) amène la question des origines et de 
l'usage de l'écriture dans I'Inde ancienne, et cette question ellemême domine toute l'histoire des textes sacrés dans l'Inde. Si l'écriture n'était pas connue, peut-on croire à l'authenticité de textes qui, comme les hymnes védiques, auraient été transmis de vive voix pendant des siècles ? Et, si l'écriture était connue, d'où venait-elle ? La plus ancienne écriture datée dans I'Inde est celle qu'ont introduite, tout au moins dans les provinces riveraines de l'Indus converties en satrapies de l'empire achéménide, les scribes du roi Darius. Et par là la Perse est introduite dans I'horizon de I'Inde d'où elle ne disparaîtra plus jamais. Les Védas et l'Avesta parlent presque la même langue, adorent en partie les mêmes divinités, pratiquent en partie le même culte. Faut-il aller plus loin encore, et n'a-t-on pas le droit de rattacher le mouvement de pensée qui produit le bouddhisme et le jaïnisme dans I'Inde au mouvement de pensée dont Zoroastre est le symbole dans l'Iran et dont Cyrus et ses successeurs sont les champions en armes ? Le concile de Râjagriha évoque encore, parmi tant de problèmes, la question de savoir dans quelle langue prêchait le Bouddha, et c'est aussitôt toute I'histoire linguistique de I'Inde ancienne qui est en jeu : ici, les écoles bouddhiques ellesmêmes sont en grave désaccord: les unes tiennent pour le sanscrit, d'autres pour le pali, pour d'autres pracrits encore ; un théologien subtil invente cette solution élégante que, par l'effet d'un miracle, chacun des auditeurs croyait entendre le Bouddha parler sa propre langue. Mais je m'attarde autour des origines quand le champ que j'ai à parcourir est d'une étendue à donner le vertige. Je me hâte d'arriver à Asoka, le petit-fils d'un contemporain d'Alexandre, et, pour reprendre une formule commode, le Constantin du Bouddhisme, en tout cas un des héros de l'histoire humaine; ses inscriptions, qu'on pourrait appeler ses Confessions, sont un modèle de sublime simple et grave. Avec lui le bouddhisme change d'aspect et de rôle ; la Communauté devient une religion d'État. Asoka inaugure la politique des missions religieuses; des apôtres qui ont reçu l'estampille officielle vont porter la Bonne Parole en dehors de I'Inde, chez les Grecs de Syrie et plus loin encore. Le contact avec l'esprit grec, un moment imposé par les conquêtes d'Alexandre, est désormais établi pour longtemps. Un royaume grec se crée sur les confins de l'Iran et de l'Inde et du Touran, qui prépare et élabore la plus large fusion humaine que le monde ait encore réalisée; des symboles hindous, même des symboles bouddhiques, gravés par des artistes grecs, ornent des monnaies de frappe grecque, encadrées de légendes en langue grecque et en langue indienne. 
Un des princes de cette longue et singulière dynastie, Ménandre passe pour s'être converti au bouddhisme ; un ouvrage fameux, les Questions de Milinda, qui se range parmi les plus anciennes productions du bouddhisme et qui subsiste encore en langue palie et en langue chinoise, montre ce disciple de la logique des Grecs aux prises, dans une controverse qu'il a volontairement provoquée, avec un docteur de l'Église bouddhique, Nâgasena ; après une joute brillante qui rappelle plus encore les Dialogues de Platon que les Sûtras des Collections bouddhiques, la sagesse transcendante de I'Inde triomphe du rationalisme hellénique; Ménandre, converti, bâtit un couvent. C'est sans doute aux exigences de l'esprit grec que le bouddhisme doit de se constituer en système ordonné, en Abhidharma. C'est plus certainement encore au contact des artistes grecs dans ces cours cosmopolites que l'art bouddhique commença de subir la transformation révolutionnaire qui l'amena à déserter ses traditions de forme, de composition, de style, et l'esprit même qui les animait pour se conformer à des canons inventés à l'usage d'une autre pensée, d'un autre sentiment, et d'autres dieux. Et les formes nouvelles ne devaient pas tarder à introduire un esprit nouveau. Ainsi la civilisation grecque, dans toute la richesse de ses manifestations, littérature, philosophie, art, histoire, politique, religion, se soude inévitablement à l'étude de la civilisation bouddhique et même $s^{\prime} y$ incorpore comme une pièce organique.

Vers le milieu du $\|^{\mathrm{e}}$ siècle avant l'ère chrétienne, une immense migration de peuples, provoquée par les victoires et les conquêtes des Huns (Hiong-nou) sur les frontières septentrionales de la Chine, porte sur le Haut-Oxus, aux confins de I'Inde, des envahisseurs scythiques, Sakas et Yue-tchi, qui chassent les Grecs, mais recueillent en partie I'héritage de leur civilisation, qu'ils essaient de combiner dans un syncrétisme original avec des emprunts à la Perse et à l'Inde. Un des rois les plus puissants du groupe Saka, qui étend sa domination sur la rive orientale de l'Indus, Gondopharès, se trouve inséparablement lié aux origines chrétiennes ; il est un des trois rois mages qui viennent, guidés par l'étoile révélatrice, adorer l'Enfant Jésus dans la crèche; c'est le roi mage Gaspar; c'est lui aussi qui, par l'entremise du courtier Abbas, engage à son service l'apôtre Thomas comme architecte, pour se faire construire un palais à la grecque, et qui attire ainsi dans I'Inde le premier messager de l'Évangile. Sur la foi de ces indices, on a tenté de remonter plus haut encore et de pousser plus loin ; on s'est demandé de bonne 
foi si les mouvements religieux qui aboutirent en Palestine à Jean-Baptiste et Jésus n'étaient pas le contrecoup d'une propagande bouddhique, si l'étrange communauté des Esséniens en particulier n'était pas une adaptation locale de la communauté bouddhique; on a cru saisir dans les Évangiles des emprunts positifs tirés de la légende et même de la littérature bouddhique; on a dressé des tables de parallèles. N'a-t-on pas essayé de spéculer sur l'apparente et trompeuse ressemblance du nom du Christ avec le nom de Krishna, le héros glorifié par le MahâBhârata et adoré encore aujourd'hui comme un avatar de Vishnou ? Ici aussi, on a cité dans les deux légendes sacrées des ressemblances, et qui sont indéniables: la naissance dans la crèche, la fuite de la sainte famille, le massacre des Innocents par l'ordre d'un tyran inquiet. On en a conclu précipitamment à un emprunt venu de l'Inde. Mais n'a-t-on pas, d'autre part, essayé d'établir que la Bhavagad-Gîtâ, l'essence de la doctrine de Krishna et aussi l'essence de la pensée philosophique de l'Inde, n'était qu'une collection de centons tirés du Nouveau Testament? Sur de pareilles questions, où la moindre parole prononcée risque de froisser des consciences dans leurs scrupules les plus ombrageux, la prudence rigoureuse de la science doit s'accompagner d'une délicatesse raffinée; les affirmations tranchantes, et de plus fondées sur des bases précaires, ne sont pas seulement méprisables, elles deviennent odieuses. Mais il n'en est pas moins vrai que la question a le droit d'être posée et d'être traitée ; des coïncidences accumulées sortira peut-être un rayon de lumière, un trait de vérité. Les principaux obstacles sont l'incertitude de la chronologie indienne, spécialement de la chronologie littéraire, et aussi l'obscurité presque impénétrable de la vie religieuse dans le monde iranien à l'époque qui entoure la naissance du christianisme. Entre le monde de la Méditerranée et le monde indien, l'I ran est le trait d'union nécessaire, et les récentes trouvailles de l'Asie Centrale prouvent que son action s'est étendue aussi à l'Est, plus loin et plus profondément que personne ne croyait. L'historien du bouddhisme n'a pas le droit d'ignorer les problèmes des croyances religieuses de I'I ran sous les Parthes Arsacides, non plus que les problèmes des origines chrétiennes.

C'est presque exactement à la naissance du Christ, en l'an 2 avant l'ère, que des textes positifs fixent la première transmission d'un sûtra de I'Inde à la Chine. Depuis l'empereur Wou des Han, la politique impériale a cherché des alliances dans les pays 
d'Occident, ouverts par les voyages de Tchang Kien, et surtout chez les Yue-tchi, ces anciens voisins de la Chine du Nord, qui ont fondé depuis un vaste empire constamment accru, de l'Oxus à I'Indus, de l'Indus au Gange. Un envoyé chinois à la cour des Yue-tchi reçoit de leur prince la communication orale d'un texte sacré du bouddhisme. La Chine avait-elle déjà reçu plus tôt des missionnaires ? La légende n'hésite pas à l'affirmer; elle place après Asoka l'arrivée d'un bonze hindou, sous le règne effervescent de Tsin Che Hoang-ti. L'histoire officielle, en Chine, date I'introduction du bouddhisme au temps des Han, vers l'an 65 de l'ère chrétienne; à la suite d'un songe fameux où il a vu un homme d'or voler au-dessus du palais impérial, Ming-ti envoie une mission chercher dans I'Inde des moines bouddhistes. Elle en ramena deux, l'histoire a préservé leurs noms : Kâsyapa Mâtanga et Tchou Fa-lan. Ils inaugurent aussitôt cette immense entreprise de traduction qui n'a pas de parallèle dans toute I'histoire du monde ancien et qui, poursuivie avec une pieuse obstination sur une durée de dix siècles, enrichit la Chine des trésors d'une immense littérature où l'Inde bouddhiste avait entassé ses rêveries, ses spéculations, ses raisonnements, ses fantaisies, ses émotions. Pour chercher une analogie, qu'on pense à l'action exercée sur le monde gréco-romain par la pensée juive, condensée dans le recueil de l'Ancien Testament, et répandue par l'Église chrétienne; mais qu'est-ce que l'Ancien Testament, en comparaison de cette immense multitude d'ouvrages, dont beaucoup ont une étendue énorme, où sont représentés tant de genres divers? La gloire de l'œuvre accomplie ne va pas d'ailleurs à l'Inde seule; elle y a eu des associés, recrutés partout où le bouddhisme s'est propagé. Parmi les premiers traducteurs, on voit déjà figurer des Iraniens; un des plus grands et des plus féconds est An Che-kao, un prince arsacide passé en Chine. A ces indices, on devine la faveur que le bouddhisme avait rencontrée dans le monde iranien. L'esprit iranien n'est pas étranger sans doute aux transformations qui renouvellent alors le bouddhisme indien et qui se réfléchissent aussitôt dans son image chinoise.

Le bouddhisme ancien était essentiellement une confrérie de moines isolés dans de pieuses retraites, à l'écart des activités humaines, appliqués à la pratique d'une discipline purement ecclésiastique qui visait à former des «Arhat», des saints purifiés de toutes les souillures, sortis à jamais de l'océan des transmigrations; leur culte se concentrait sur le souvenir du Bouddha 
Sâkyamuni, ses reliques, ses lieux saints. Puis, brusquement, à une date qu'il est impossible de préciser, mais qui ne doit pas s'éloigner beaucoup des premiers temps de l'ère chrétienne, tout change: l'activité, auparavant condamnée, est alors glorifiée, sanctifiée, sous la condition d'être dégagée des intérêts personnels et d'être employée au salut d'autrui ; la Bodhi, la connaissance suprême qui fait les Bouddhas, est accessible à tous les êtres ; plutôt même, ils la portent en eux de toute éternité, mais méconnue par l'effet des impuretés contractées, comme le miroir sous la poussière qui le ternit; le saint est le Bodhisattva, l'être qui s'est voué à l'exercice des perfections actives pendant des périodes incalculables d'existences successives; l'univers grandi à l'infini est rempli d'une multitude infinie de Bouddhas dont la compassion efficace ne cesse jamais d'agir ; un d'eux, Amitâbha, « la lumière illimitée » efface tous les autres par sa popularité ; il trône au milieu des Élus dans un Paradis, Sukhâvati, «L'Heureuse », où les âmes des justes attendent, parmi des félicités angéliques, I'heure du salut définitif. II a pour assistant une sorte de fils spirituel, le Bodhisattva Avalokitesvara, «le Seigneur qui regarde d'en haut » modèle accompli de charité vigilante. II a pour pendant un véritable Messie, le premier des Bouddhas à venir, le Bodhisattva Maitreya, «issu de Mitra », qui attend dans un Paradis, lui aussi, I'heure où il viendra s'asseoir sous l'Arbre du Dragon pour prêcher à son tour la Loi du Salut universel. Autant d'idées, de croyances, de noms que I'Inde n'explique pas, qui sont aussi étrangers au brahmanisme ancien qu'au bouddhisme ancien; autant d'idées, de croyances, de noms qui sont familiers à l'Iran Zoroastrien, d'où ils ont passé déjà vers l'ouest dans le judaïsme des prophètes, et de là dans la doctrine du christianisme. Parmi les Perfections que le Bodhisattva doit conquérir, figure au premier rang la « Perfection de la Sapience » Prajnâ-Pâramitâ, qui est exaltée comme la Mère des Bouddhas. Comment ne pas penser à cette secte des Gnostiques, de Basilide, de Valentin, secte religieuse bien plus qu'école philosophique, surgie sur le territoire iranien du christianisme, et qui proclame le salut par la Gnose, « gnôsis » équivalent grec du sanscrit «prajñâ » qui lui est même en partie identique? Et comme pour mettre hors de doute la collaboration du génie religieux de I'Iran avec celui de l'Inde dans cette période tourmentée et féconde où le christianisme grandissant inquiète l'Empire romain, où la dynastie nouvelle des Sassanides tente en Perse la restauration intégrale de l'orthodoxie avestique, vers le milieu du ${ }_{I I I^{\mathrm{e}}}$ siècle, un Iranien, Mani, imagine une combinaison éblouis- 
sante du Zoroastrisme, du Bouddhisme, et du Christianisme ; à l'un il emprunte le dualisme fondamental, la Lutte des Deux Principes du Bien et du Mal ; aux deux autres il emprunte leur appareil légendaire et mythologique, leur organisation militante, leur pratique de la confession, leurs formes littéraires. La Vie du Bouddha elle-même se plie à devenir entre les mains de Mani et de ses disciples, un instrument de propagande; leur contrefaçon, qui fausse la doctrine, mais qui retient les lignes essentielles: l'éducation au palais, les quatre rencontres, la fuite, l'entrée en religion, les apologues, obtient un succès universel; on en a retrouvé des fragments à Tourfan, écrits en turc oriental ; apportée, dit-on Jérusalem par un moine soit naïf, soit imposteur, elle introduit dans l'Église chrétienne un nouveau saint, Joasaf, où transparaît encore le nom de Bodhisattva, en persan Budsaf ; accueillie partout avec ravissement, elle passe dans toutes les langues pratiquées par le christianisme; l'église du moyen âge n'a pas eu de récit plus populaire. La religion de Mani, qu'il contresigne de son martyre, est assez forte pour menacer les doctrines qu'il a copiées. Vers l'Occident, elle se répand dans l'Asie Mineure, dans l'Afrique du Nord où le manichéisme séduit la jeunesse de saint Augustin, en Espagne; jusqu'en plein moyen âge, elle lutte pour s'implanter dans le sud de la France ; l'Église chrétienne exaspérée poursuit d'une rancune implacable l'ennemi qui l'a fait trembler. Vers l'Est elle ne semble pas prendre pied dans I'Inde; mais elle engage la lutte avec le Bouddhisme sur les domaines qu'il est en voie de s'annexer: l'Asie centrale et la Chine.

Pour atteindre la Chine, les missionnaires du bouddhisme indien avaient dû suivre les deux routes que les conquêtes des Han avaient ouvertes; elles longeaient toutes deux l'une par le sud, l'autre par le nord, les bords extrêmes d'un immense désert de sable où s'espaçaient de rares oasis; des villes s'y étaient établies, peuplées d'un mélange de races hétérogènes, Indiens, Iraniens, Turcs et même des Aryens de la souche italo-celtique, arrivés là sans qu'on sache ni quand, ni d'où, ni par où ils étaient venus. Le bouddhisme aussitôt introduit avait accompli là son œuvre de civilisation; messager du génie indien, il avait cultivé les parlers locaux, les avait affinés, les avait appelés à la dignité littéraire. Les fouilles entreprises depuis une vingtaine d'années à Khotan, à Kouteha, à Kharaehar, à Tourfan ont révélé des langues et des littératures oubliées, nées des missions bouddhiques et mortes pour la plupart avec la disparition du bouddhisme. Un 
des peuples qui occupent aujourd'hui la scène du monde, les Turcs, doivent sans doute la première culture de leur langue aux missionnaires bouddhistes, bientôt suivis par les missionnaires manichéens; les deux confessions se disputèrent longtemps ce peuple aux croyances instables avant que I'Islam l'eût rangé sous sa bannière de combat.

Au moment même où Mahomet inaugurait la propagande par le sabre qui devait coûter si cher aux pacifiques disciples du Bouddha, le bouddhisme gagnait en dehors de l'Inde, sur le versant nord de l'Himalaya, un domaine nouveau qui devait lui servir jusqu'à nos jours de citadelle inviolée, le Tibet. Au début du $\mathrm{VII}^{\mathrm{e}}$ siècle, le roi Srong-btsan-sgam-po avait réuni sous son autorité les tribus encore à demi sauvages dispersées dans les hautes vallées tibétaines; il avait contraint d'abord son voisin hindou, le roi du Népal, puis le lointain empereur de Chine luimême à lui donner chacun une princesse comme épouse; les deux reines, également zélées à servir le Bouddha, et plus tard adorées comme deux incarnations de la déesse sauveuse, Târâ, amenèrent avec elles des moines, des livres, des images; l'œuvre accomplie dans l'Asie centrale se renouvela sur ce terrain plus rude encore que les sables du Turkestan. Au bout d'un siècle, la religion était si florissante, la langue si développée et affinée qu'on put y entreprendre la traduction intégrale des textes sacrés ; inauguré sous l'inspiration de Padma sambhava, qui était originaire du pays d'Uddiyâna (la haute vallée du Svat, affluent de la rivière de Caboul), le travail se poursuit continuement pendant plusieurs siècles, en dépit des persécutions passagères ; il aboutit aux deux vastes collections du Kanjour et du Tanjour, qui contiennent l'une les enseignements du Bouddha, l'autre ceux des Pères de l'Église, traduits la plupart d'originaux sanscrits ; quelques rares ouvrages y ont été traduits du pali, du chinois, et même de langages aujourd'hui disparus. Plus étendus que les collections chinoises, ils sont vraiment le reflet d'une civilisation entière; autour du bouddhisme y trouvent place la grammaire, la métrique, la logique, la rhétorique, la poésie, l'astronomie, la peinture, la statuaire. Quand s'abattit sur l'Inde, à partir de l'an mil, le désastre des invasions musulmanes, quand les couvents de Nâlandâ, de Vikramasilâ, d' Uddandapurî furent détruits, les bibliothèques brûlées, les moines massacrés ou dispersés, le Tibet, avec le Népal voisin, recueillit et sauva les derniers restes de la culture bouddhique de I'Inde ; le bouddhisme tibétain se trouva même assez vivace pour propager à son 
tour la civilisation bouddhique. Le petit fils du fameux Gengis khan qui avait ajouté le Tibet à son immense empire, Koubilai khan, se convertit au bouddhisme sous l'influence du lama tibétain Saskya pandita ; il donna l'ordre aussitôt (1251) de traduire dans sa langue maternelle, le mongol, l'ensemble des textes sacrés; il fit aussi réviser les collections chinoises du Tripitaka, fit comparer les textes chinois aux textes tibétains et en fit dresser un catalogue parallèle. Quand les Mandchous à leur tour devinrent au XVII ${ }^{\text {e }}$ siècle les maîtres de l'Empire chinois, ils voulurent eux aussi posséder dans leur propre langue les textes sacrés du bouddhisme qu'ils avaient adopté.

Au sud-est de l'Asie, sur la route de mer sinueuse et difficile qui va des ports de l'Inde aux ports chinois, l'œuvre du bouddhisme n'avait été ni moins grande, ni moins féconde. Vers l'aube de l'ère chrétienne, les progrès rapides des connaissances maritimes, entre autres la constatation scientifique de la périodicité des moussons, avaient ouvert des communications régulières et suivies entre I'Inde et les pays d'Extrême Orient ; des contacts imprévus s'amorçaient: un marchand grec d'Égypte, dès la fin du I $^{\text {er }}$ siècle, envoyait un de ses capitaines visiter les ports de I'Insulinde et de l'Indochine ; un peu après, un autre marchand, qui se donnait comme l'ambassadeur de l'empereur romain Antoen, l'Antonin Marc-Aurèle, débarquait au Tonkin ; à la même époque, et dans le Tonkin aussi, dans une famille de colons originaires du pays de K'ang, la contrée de Samarcande, naissait le futur moine Seng-hoei, qui devait s'illustrer parmi les plus anciens traducteurs des textes sanscrits en Chine. Dès le début du ${ }_{11 I^{\mathrm{e}}}$ siècle, un grand royaume de civilisation indienne, le Founan, dominait sur les bouches du Ménam ; le bouddhisme y était assez prospère pour fournir à la Chine des traducteurs de textes sanscrits jusqu'au $\mathrm{VI}^{\mathrm{e}}$ siècle. Le Fou-nan cédait alors la place au royaume de Kambuja, dont le Cambodge actuel préserve encore le nom. Ce que le bouddhisme indien avait pu accomplir en Kambuja, des centaines d'inscriptions le proclament encore, rédigées en vers sanscrits d'une facture souvent raffinée ; plus fièrement encore le proclament les magnifiques monuments élevés par le génie des architectes khmers, dressant jusqu'aujourd'hui leurs masses élégantes ou colossales au milieu des forêts qui n'ont pu triompher d'eux. Au $\mathrm{XI}^{\mathrm{e}}$ siècle encore, alors que se manifestait déjà l'irrémédiable décadence du bouddhisme dans I'Inde, la « Terre de l'Or » Suvarnabhûmi, comme on continuait à nommer la péninsule d'outre-Gange, gardait un tel prestige de 
science qu'elle voyait arriver, pour étudier dans ses écoles, Atîsa, la dernière gloire du bouddhisme au Bengale, et qui devait s'inscrire ensuite parmi les plus grands noms de l'église tibétaine. A partir du $\mathrm{xII}^{\mathrm{e}}$ siècle, la poussée des invasions venues du nord renverse les anciens États et en crée de nouveaux, la Birmanie, le Siam ; le bouddhisme de langue sanscrite et de doctrine mahâyâniste est expulsé, mais la place est aussitôt prise par une autre branche de la même religion, l'église hînayâniste et palie de Ceylan envoie ses missionnaires qui triomphent, et c'est elle qui reste encore aujourd'hui maîtresse des confins du Bengale à la Cochinchine, en Birmanie, au Siam, au Laos, au Cambodge.

Sur le littoral de la presqu'île indochinoise, dans le pays qui est aujourd'hui l'Annam, la civilisation indienne avait aussi, dès les premiers temps de l'ère chrétienne, créé une colonie d'où sortit un grand royaume, le Champa. Ici aussi, comme au Cambodge, inscriptions et monuments racontent la longue gloire du bouddhisme indien, sanscrit et mahâyâniste ; ici aussi, l'invasion venue du nord a balayé le pays vers le $x v^{e}$ siècle, mais ici, c'est le bouddhisme chinois qui a occupé la place devenue libre.

Dans l'archipel Indien, les deux grandes îles Java et Sumatra, souvent considérées comme la même terre et réunies sous un même nom, avaient reçu dès le début de l'ère chrétienne une civilisation hindoue. Devancé par le brahmanisme, le bouddhisme ne tarda pas à l'égaler, et souvent à le surpasser. Au VII ${ }^{\mathrm{e}}$ siècle, le royaume de Srîvijaya, à la pointe sud-est de Sumatra, était le siège d'une véritable université bouddhique où, comme à Koutcha dans le Turkestan, la civilisation de l'Inde et celle de la Chine se rencontraient en de féconds échanges. Les monuments de Java, et entre tous le célèbre Boro-Boudour, attestent la ferveur et la prospérité de la foi jusqu'à la fin du premier millénaire de l'ère chrétienne. La littérature de Java prouve la persistance et le pouvoir du bouddhisme mahâyâniste jusqu'au XIV e siècle. Mais I'I slam vient rejoindre à travers les mers le rival qu'il a déjà terrassé sur le continent asiatique; le bouddhisme succombe comme il a déjà succombé en Bactriane, dans l'Inde, au Turkes$\tan$.

Dans ce tableau si chargé, et pourtant si sommaire, je n'ai pas encore introduit les grands pays de l'Extrême Orient, la Chine, la Corée, le Japon. Mais ici, je ne puis penser même à résu- 
mer ce qui est le fond et la substance de leur propre histoire ; en Chine depuis les seconds Han, en Corée depuis le vi ${ }^{\mathrm{e}}$ siècle, au Japon depuis Shotoku (593) le bouddhisme est partout doctrines, systèmes, croyances, institutions, politique, architecture, sculpture, peinture, sur tous les domaines, il est un facteur capital ; sans lui, rien ne s'explique; autour de lui tout s'éclaire et s'ordonne. Je voudrais seulement rappeler comment, parvenue au terme de son expansion vers l'est, la civilisation bouddhique y retrouve justement le contact qu'elle avait perdu avec l'Occident chrétien. Les deux religions, bouddhisme et christianisme, s'étaient souvent rencontrées au cours de leurs vicissitudes sur le continent asiatique. Le Nestorianisme, précurseur hérétique des missionnaires jésuites, avait dès les T'ang emprunté pour sa propagande le vocabulaire du bouddhisme, témoin l'inscription de Sian-fou, comme le bouddhisme avait, à ses débuts en Chine, emprunté en le déformant le vocabulaire du taoïsme; parfois même les prêtres des deux confessions avaient coopéré de façon inattendue : témoin cette prétendue traduction de sûtra due à la collaboration du bonze hindou Prâjna et du prêtre nestorien Adam, qui fut déférée à l'empereur et condamnée comme apocryphe. Encore au XIII ${ }^{\mathrm{e}}$ siècle, Marco Polo se rencontrait avec des bonzes à la cour de Khoubilai Khan et l'envoyé de Saint Louis, Guillaume de Rubrouck, en trouvait autour du mongol Mangou khan. Mais il était réservé aux premiers Jésuites débarqués au Japon de faire connaître à l'Europe par des informations précises et copieuses le nom de «Xaca », c'est-à-dire Sâkyamuni, les institutions et l'organisation religieuses du bouddhisme. Les Jésuites de la Chine à leur tour découvrirent dans ce pays la religion de «Foe » qu'ils décrivirent sans se douter qu'il s'agissait du même personnage, du même culte. Puis ce fut au Siam que l'envoyé de Louis XIV, La Loubère, découvrit le bouddhisme sous son aspect pali, comme la religion des «talapoins », le Patimouc, transcription remarquablement exacte du pali «Pâtimokkha » le livre de la confession des moines. Au milieu du XVIIIe siècle, les Capucins trouvaient au Tibet une autre forme du bouddhisme, le lamaïsme; leur pieux historien Georgi, travaillant à Rome sur leurs notes, n'hésitait pas à y reconnaître une contrefaçon démoniaque du christianisme due à l'éternelle malfaisance des Manichéens. Ainsi, d'un bout à l'autre de son histoire, la civilisation bouddhique est incessamment solidaire des civilisations de l'Occident. 
Mais en face de ces civilisations, elle ne cesse pas de maintenir son originalité irréductible. Dégager les traits permanents qui constituent cette originalité, sous la diversité des races, des langues, des nationalités, c'est une tâche compliquée qui dépasserait le cadre où je dois me limiter. Je me contenterai d'indiquer que, au témoignage des voyageurs les moins prévenus, les peuples bouddhistes donnent une impression toute particulière de bonheur. Pour une religion si souvent taxée de pessimisme, l'observation est singulière. Cependant elle nous aide peut-être à saisir un des traits réels et profonds de la civilisation bouddhique. Une civilisation, c'est une conception de la vie humaine traduite du langage philosophique dans toutes les activités d'une société organisée. Le bouddhisme ne fait pas de l'existence un drame tragique, un point entre deux infinis où se joue une éternité de salut ou de damnation ; ce n'est qu'un accident éphémère dans une série de longueur incommensurable; la nature n'est pas un décor, un simple cadre ; animaux, plantes et jusqu'à la matière brute, ne sont, tout comme l'homme lui-même, que des stages temporaires dans l'universelle métamorphose de la vie; une immense communion rapproche tous les êtres, depuis les hauteurs du ciel jusqu'aux profondeurs des enfers, soumis tous à la même loi du karman qui développe à l'infini les conséquences morales des actes une fois commis, loi qui serait implacable s'il n'était donné aux vertus cardinales, sagesse, douceur, pitié, d'annuler cette force aveugle et d'assurer à jamais la béatitude dans la paix du Nirvâna. Voilà, si je ne me trompe pas, l'inspiration qui pénètre la civilisation bouddhique, qui l'a fait vivre, grandir et qui lui assure une place glorieuse dans l'ensemble des civilisations. Elle est un des points culminants qui commandent les perspectives de I'histoire humaine; elle la domine du côté de l'Orient, comme le christianisme fait de l'Occident, comme I'Islam du Midi ; mais pour que le regard de l'esprit puisse embrasser la vue qu'elle découvre, il lui faut deux auxiliaires : un cœur vraiment humain, une culture vraiment humaine. 


\section{Civilisation brahmanique}

$\underline{\text { Retour au Sommaire }}$

Une civilisation est un système de croyances, d'institutions, de pratiques élaboré par une communauté humaine au cours de son développement historique en vue d'assurer à ses membres la réalisation collective d'une forme de bonheur spéciale, considérée naturellement comme la mieux adaptée aux tendances instinctives et aux traditions conscientes de ce groupe, et conséquemment aussi considérée comme une forme de bonheur supérieure celles que peuvent poursuivre ou réaliser les autres groupes. Par le fait qu'elle exige de tous les participants une adhésion aveugle ou réfléchie, mais susceptible de s'affirmer par des manifestations actives qui vont jusqu'au sacrifice de la vie, une civilisation n'existe pas sans un certain nationalisme, sans un sentiment de préférence qui implique forcément un certain dédain pour les civilisations différentes.

Qu'il y ait une civilisation indienne, personne, je pense, ne songerait à le contester. Nulle part la conception du bonheur, ce qu'on appelait autrefois «le souverain bien » summum bonum - n'a pris des formes plus singulières ou plus originales ; nulle part cette conception n'a mieux réussi à pénétrer la vie entière, au point d'isoler pratiquement la société qui l'avait adoptée ; nulle part, le dédain de l'étranger ne s'est affiché avec plus de franchise. La croyance fondamentale qui supporte tout l'édifice, c'est avant tout l'irréalité transcendante du monde phénoménal; alors que pour les autres groupes humains les sens sont les témoins et les garants irréfutables, pour l'Hindou ils ne sont que des maîtres d'erreur et d'illusion; la seule réalité immédiate et incontestable est celle que donne intérieurement la conscience, l'intuition qui révèle, au-dessous des aspects trompeurs du Moi, l'Absolu, soit sous une forme positive où il est 
l'être en soi, soit sous une forme négative où il est le Néant. Le monde des phénomènes, mensonger et haïssable, est régi par une loi fatale, implacable: l'acte est la résultante morale d'une série incommensurable d'actes antérieurs et le point de départ d'une autre série incommensurable d'actes qui en seront les effets indéfiniment transformés. Le système d'actes qui constitue la personnalité temporaire se transforme dans un autre système qui le continue en constituant une nouvelle personnalité également temporaire, et ainsi de suite dans l'éternité du temps. La vie, considérée sous cet aspect, apparaît comme la plus effroyable des peines, comme une éternelle perpétuité de personnalités fausses, à prendre et à quitter sans connaître jamais le repos. Le souverain bien ne peut être dès lors que la Délivrance, l'acte sublimé d'où sont éliminées toutes les forces causatives, et qui anéantit à tout jamais pour un système donné la puissance créatrice de l'illusion.

De la métaphysique, la doctrine, en passant dans la vie sociale, aboutit logiquement à l'organisation des castes. Si la naissance présente est la résultante du total des actes antérieurs, la société n'a qu'à constater et à maintenir ce qu'elle est incapable de changer. L'aristocratie du sang est une aristocratie de droit suprême, de droit naturel - on ne peut pas dire: de droit divin, puisque la volonté des dieux n'y peut rien changer tout comme la volonté humaine; né dans les rangs inférieurs de la société, l'individu est de ce fait même désigné à la société comme le porteur d'une « hérédité morale » qui agit avec plus de rigueur et d'intransigeance que «l'hérédité physiologique » dans nos croyances actuelles. Ainsi la société tend à s'organiser dans une hiérarchie compliquée de groupes fermés; le degré occupé par chacun des groupes est déterminé par le degré d'estime que le consentement commun, ou plutôt que les nécessités communes, accordent au genre d'occupation que ce groupe exerce. Telle est la « caste», un nom qui a fait tristement fortune; il va de pair, dans l'usage universel avec le terme de «paria », qui désigne partout aujourd'hui ceux à qui la société n'a pas réservé de place reconnue, qui n'en sont que le déchet et le rebut. C'est I'Inde qui a eu le fâcheux honneur de donner au monde ce mot de «paria »; il a passé, des parlers dravidiens de l'Inde du Sud, dans les récits des voyageurs, dans la littérature, et dans la vie. Quant au terme de « caste » s'il n'est pas indien (c'est des Portugais qu'il nous est venu, comme tant d'autres; il rappelle le temps, si lointain déjà, de la suprématie portugaise aux Indes), 
les Portugais l'ont appliqué à une institution spécifiquement indienne. On parle volontiers de «castes» maintenant dans le monde entier; mais nos sociétés même les plus hiérarchisées n'ont rien qui puisse se comparer avec la caste indienne. Dans I'Inde, la caste vous prend à la naissance et elle vous possède jusqu'à la mort; on n'en sort que pour devenir un outcast, un forban que la loi ne connaît plus et que la société entière a rejeté. La caste est une cellule de la société organisée comme une société intégrale ; elle a ses coutumes, ses tribunaux; elle prononce des peines, inflige des amendes, qu'il s'agisse des castes les plus nobles ou au contraire des castes les plus méprisées du plus pauvre des villages. Elle enferme l'individu dans une espèce de geôle sociale; on ne peut prendre femme légitimement qu'à l'intérieur de sa caste; on ne peut prendre son repas en commun qu'avec des personnes de sa caste ; une goutte d'eau à boire, une poignée de riz acceptée des mains d'un homme de caste inférieure entraîne une impureté si grave qu'elle peut amener la déchéance irréparable, l'expulsion hors de la caste. Les voyageurs, les sociologues, les indianistes ont souvent représenté I'Inde comme divisée en quatre castes : les brahmanes qui sont la caste sacerdotale; les kshatriya qui sont la caste militaire ; les vaisya qui sont la caste marchande; les sûdra qui sont la caste paysanne. Les trois premières castes: brahmane, kshatriya, vaisya, reçoivent sous des formes différentes et à des degrés différents, une initiation de caractère religieux qui compte comme une seconde naissance et qui fait d'eux des « deux fois nés » des «dvija ». Les sûdra n'ont pas ce privilège ; ils ont cependant un statut social défini qui leur reconnaît surtout des devoirs, mais qui leur assure une place dans l'intérieur de la communauté. II est une classe d'êtres humains que la communauté n'a pas admis : ce sont les « parias ou comme on dit en sanscrit, les « chandâla »; leur présence est une impureté, leur contact est une souillure ; ils ne sont tolérés qu'à l'écart des villes ou des villages, pêle-mêle avec les ordures et les animaux impurs. Tel est, je le répète, le tableau de la société indienne comme on le trouve généralement tracé, et la littérature indienne semble bien, à première vue, en confirmer l'exactitude. Non seulement le théâtre, l'épopée, le conte, les inscriptions parlent à chaque instant des « quatre castes »; mais les Codes classiques prennent aussi pour base la division de la société en quatre castes.

Cependant, il ne faut pas s'y tromper ne s'agit là que d'une simplification schématique. La réalité est infiniment plus com- 
plexe et plus variée. Sans cesse, à travers les longs siècles de I'histoire indienne, des castes naissent, s'éteignent, se transforment, je veux dire des groupes humains liés par la même coutume, assujettis aux mêmes pratiques spéciales, voués à une occupation particulière, enfermés dans les obligations du mariage et des repas. L'histoire sociale de l'Inde, plus obscure et plus enchevêtrée encore que son histoire politique, consiste essentiellement dans la concurrence de ses innombrables groupes, les uns ambitieux de s'assurer un rang de plus en plus élevé dans la hiérarchie sociale, les autres jaloux de maintenir leur position privilégiée contre les empiètements de leurs rivaux. Pour prendre un exemple concret dans le temps présent, je citerai le cas du Bengale actuel, une des régions les plus modernisées, les plus avancées de l'Inde; l'ensemble des castes brahmaniques s'y partage en deux groupes rivaux: les uns, revendiquant la suprématie au nom de la pureté du sang, prétendent descendre des brahmanes authentiques, appelés jadis dans le pays par un roi pieux, Adi Sûra; les autres plus relâchés dans leurs pratiques, n'en persistent pas moins à se considérer comme les égaux des premiers. Et d'autre part, dans ce même Bengale, les nombreux groupes classés sous la rubrique commune de «Kâyastha » scribes, continuent à être rangés par les brahmanes clans la grande caste des Sûdra, en dehors et au-dessous des trois castes appelées à l'initiation religieuse; mais dans la pratique, les Kâyastha, souvent instruits et souvent aussi enrichis, prétendent marcher de pair avec les brahmanes et même se considèrent volontiers comme supérieurs aux brahmanes.

Quoi qu'il en puisse être de ces prétentions et de ces conflits, la suprématie du brahmane reste dans l'ensemble le dogme incontesté qui sert de base à l'organisation hindoue. Et, comme il arrive d'ordinaire en pareil cas, le privilège a créé un droit de fait ; la moyenne de la caste brahmanique est nettement supérieure au reste de la population, tout au moins comme valeur intellectuelle. Rabindranath Tagore, en qui le Bengale salue son plus grand poète et que l'Inde vénère comme son génie national, est de famille brahmanique; sa généalogie le rattache même à un des chefs de famille appelés jadis au Bengale par Adi Sûra. II appartiendrait donc à l'élite légale du brahmanisme si, par une fantaisie amusante du sort, un des ancêtres n'avait été frappé d'exclusion, « outcasté », pour avoir, paraît-il, accepté de manger en commun avec des étrangers, soit Musulmans, soit Chrétiens. Pour occuper définitivement le rang suprême, la caste 
brahmanique avait dû subir de violents assauts ; la caste militaire, les Kshatriya, n'avait pas volontiers cédé le pas à la caste sacerdotale. La tradition brahmanique elle-même a conservé le souvenir vivace d'un personnage d'origine guerrière, Visvâ mitra, qui avait réussi, en dépit de résistances furieuses, à forcer l'entrée de la caste brahmanique et même à y occuper une des places d'honneur; le conflit entre Visvâmitra et Vasishtha, le champion de l'orthodoxie intransigeante, est resté depuis les temps védiques un lieu commun de la littérature. Récemment encore, le plus savant des brahmanes du Bengale, et aussi un des plus orthodoxes, Mahâmahopâdhyâya Haraprasâd Sâstrî, a repris ce vieux thème pour en tirer un poème épique où l'inspiration du Paradis Perdu de Milton vient se mêler curieusement à l'inspiration du Râmâyana, et où Visvâmitra, l'adversaire du privilège brahmanique, se transforme dans une sorte de Prométhée. La naissance du bouddhisme et du jaïnisme témoigne d'un mouvement analogue ; le Bouddha Sâkyamuni, le Jina Mahâvîra sortent l'un et l'autre d'une famille princière de la caste des kshatriya; en prétendant enseigner aux hommes la voie de la Délivrance, ils empiètent tous deux sur le privilège que les brahmanes veulent se réserver. Un des champions de l'orthodoxie brahmanique, Kumârila Bhatta, qui florissait plus de mille ans après le Nirvâna, reproche encore au Bouddha d'avoir enfreint les devoirs de sa caste. "Quel droit avait-il à prêcher la pitié ? demande Kumârila ; il était né kshatriya et le devoir de sa caste lui prescrivait de prendre les armes et de combattre. » Voilà, nettement exprimée, la conception définitive qui commande la civilisation indienne; c'est aussi la conception que la célèbre Bhavagad Gîtâ expose en vers magnifiques. On sait dans quel cadre se déroule le dialogue de la Bhavagad Gîtâ. Le héros Arjuna est monté sur son char; le divin Krishna, son inséparable ami, est debout à côté de lui et dirige l'attelage. Au moment de frapper ses adversaires, qui sont ses cousins, le sensible Arjuna hésite et pleure ; Krishna le réconforte et lui prêche la loi du salut «Fais le devoir qui t'appartient ; un kshatriya ne doit pas refuser la bataille, l'acte est pur s'il est accompli sans aucun esprit d'intérêt personnel. » «Le devoir propre (sva-dharma), telle est la règle à suivre; l'ordre social n'est que la collection des devoirs propres qui s'imposent à chacun des groupes ; . prétendre exercer des vertus qui n'appartiennent pas au groupe, à la caste, c'est compromettre l'ordre social, et, puisque l'ordre social est une fonction de l'ordre religieux, c'est commettre un péché. 
Une conception de la vie aussi foncièrement aristocratique ne pouvait manquer de réagir sur toutes les manifestations de la civilisation indienne et de leur imprimer un caractère original. Prenons tout d'abord les faits du langage. Dans toutes les sociétés, le langage est le symbole par excellence de l'unité du groupe; le nom de la langue est identique au nom dont le groupe se sert pour se désigner : la langue des Assyriens est la langue assyrienne; la langue des Latins est la langue latine; la langue des Français est la langue française; la langue des Japonais est la langue japonaise. Dans la plupart des cas, l'identité est si forte que le nom national suffit à désigner la langue, sans autre addition. On dit: «parler français; speak english; deutsch sprechen ». Mais on ne dit pas : parler indien, car il n'y a pas de langue indienne; il y a des langues indiennes, des langues parlées par des groupes divers dans I'Inde. Néanmoins il existe une langue littéraire commune à toute l'Inde, qui y est cultivée depuis des milliers d'années et qui n'est pas encore morte, quoiqu'elle n'ait jamais été vivante. Elle est connue dans l'Inde entière sous le nom que nous continuons à lui appliquer; c'est le « sanscrit ». Mais cette désignation n'a rien à faire avec la nomenclature géographique. «Sanscrit » signifie simplement « raffiné »; on serait tenté au premier abord de rapprocher cette notion de celle qu'exprime chez nous le terme de «langue académique ». Mais ce seul rapprochement fait éclater la différence profonde des deux conceptions.

La langue académique est la langue fixée par une académie, par une réunion d'hommes reconnus comme des autorités en raison de leur valeur littéraire ou sociale. Le mot samskrita implique une tout autre idée; il s'associe naturellement à l'idée d'une opération de caractère religieux qui fait passer du domaine du profane au domaine du sacré. Les samskâra, les actes qui ont pour objet de rendre samskrita la personne ou la chose, sont exactement ce que l'Église chrétienne appelle des "sacrements », les cérémonies de la naissance, du mariage, des funérailles, etc. Et, de fait, le samskrita est bien une langue sacrée ; c'est la langue des dieux, et sur la terre elle est réservée à ceux qu'on appelle les dieux de la terre, les brahmanes et les rois. C'est en principe la langue de la prière, une langue difficile à manier comme tout ce qui participe au sacré, car la force contenue dans le sacré peut se retourner contre celui qui ne sait pas la manier. Les plus anciens traités d'exégèse védique, les Brâhmanas content plus d'une histoire où une prononciation fautive 
ou bien une accentuation défectueuse ont abouti aux résultats les plus désastreux. D'après les règles de l'art dramatique, règles qui ont été suivies avec une docilité aveugle par tous les auteurs qui ont écrit pour le théâtre, ni les femmes (à l'exception des religieuses bouddhiques, que leur ordination a fait passer dans le sacré), ni les marchands, ni les castes inférieures ne doivent parler sanscrit sur la scène. Les théoriciens, et la pratique à leur suite, admettent quatre variétés de dialectes, que les grammairiens ont d'ailleurs réglementées aussi sévèrement que le sanscrit, et ces quatre dialectes sont répartis entre les personnages qui ne peuvent parler le sanscrit d'après la hiérarchie de leur condition sociale. Ici encore, si on acceptait à la lettre les données du théâtre comme l'image de la réalité, on retrouverait une division linguistique en cinq catégories qui serait symétrique à la division en quatre castes, plus la classe des hors-castes, que les Codes prennent pour base de l'organisation sociale; mais ici aussi on se trouve en présence d'une simplification schématique. En fait, chacun des groupes isolés dont l'ensemble constitue une caste tend et aboutit à se créer dans les cadres même de la langue commune tout un système de particularités conscientes ou irréfléchies qui lui sert de symbole : témoin dans toutes les sociétés du monde les argots professionnels, argots d'atelier, argots d'école, langage des francs-maçons, etc. On discute fréquemment, et encore aujourd'hui, dans I'Inde et ailleurs, la question de savoir si le sanscrit a jamais été une langue parlée, et quand, et où ? L'analogie des autres langues littéraires, souvent invoquée en guise d'explication, n'a rien à faire dans ce cas ; le sanscrit est solidaire d'une civilisation toute particulière, et c'est cette civilisation seule qui peut rendre raison de son existence. Le sanscrit est un type de langage exclusivement aristocratique et religieux. Pour en donner approximativement une idée, il faudrait rappeler les «langues sacrées » qui se conservent dans les sociétés du type rudimentaire, et dont l'usage d'ailleurs obligatoire est limité à certaines périodes et à certaines cérémonies. Le sanscrit est le trait d'union entre le ciel et la terre, mais il ne touche la terre que par les cimes. Si, de langue religieuse, il passe au rôle de langue littéraire, ce n'est point pour se compromettre avec le vulgaire ; c'est pour donner à l'élite un régal intellectuel qu'elle seule au reste est capable d'apprécier.

Le beau, en effet, n'est pas accessible à tous dans une telle conception de la vie. II est de règle partout qu'un privilège en entraîne un autre, mais nulle part ailleurs les privilèges ne 
s'entraînent avec une pareille rigueur, j'allais dire avec une pareille férocité de logique. Le problème de l'émotion esthétique, qui a pu embarrasser ailleurs les philosophes, se résout avec une simplicité déconcertante en partant de la doctrine du karman, c'est-à-dire de la transmigration et de la rétribution. L'aptitude à jouir du beau est, elle aussi, une récompense pour ainsi dire automatique des mérites acquis au cours des existences antérieures; elle va donc de pair avec le privilège de la naissance. L'âme, si on peut se servir de ce mot pour désigner le siège de la personnalité, conserve de ses impressions dans les vies antérieures une sorte d'imprégnation qui la rend délicatement sensible aux rappels, aux évocations, plus exactement encore aux suggestions. L'art véritable consiste à choisir et à isoler le minimum de détails susceptibles de provoquer par correspondance un état d'âme déterminé chez les individus bien préparés. L'expression directe qui est la loi constante de l'art en Occident, n'est pour l'artiste et l'esthéticien hindou qu'une forme grossière et méprisable. L'imitation de la nature, si exacte qu'elle puisse être, n'a rien à faire avec le beau; ce n'est qu'une besogne de métier, qui ne porte en elle aucune source d'émotion noble. II n'y a de noblesse que dans le symbole, et justement dans la mesure ou il a éliminé les données positives pour n'en garder que le substrat le moins matériel.

La conséquence nécessaire, c'est que l'art indien dans toutes ses manifestations est essentiellement lyrique. En poésie, le simple aspect du vers rend le fait saisissable et frappant. Le vers indien, à quelque variété métrique qu'il appartienne, est toujours en réalité une stance, une période musicale complète, constituée par un balancement régulier de parties intégrantes, mais strictement limitée dans son étendue qu'il lui est interdit de déborder. La poésie grecque s'était créé dès le temps d'Homère un outil merveilleusement assoupli pour la narration épique ou didactique, autrement dit pour représenter et suivre l'action; le vers héroïque, l'hexamètre, est, comme son nom l'indique, un simple système de six mesures, de cadences à la fois définies et variables, qui s'emboîte sans difficultés dans un système plus large, composé à volonté de plusieurs hexamètres ou de plusieurs fragments d'hexamètres. L'Inde a aussi un vers héroïque et didactique, le Sloka, qui est un système de quatre membres composés chacun de huit syllabes; mais c'est un système bloqué dans lequel la phrase commence et s'achève ; chaque sloka est une unité absolue qui peut s'isoler du reste sans affecter, 
dans leur forme extérieure tout au moins, les sloka voisins. Si toutefois on veut essayer de goûter la perfection propre de l'art indien, c'est dans d'autres stances d'un type métrique plus savant qu'il faut le chercher. On peut y voir avec quel art raffiné les touches s'accumulent, se juxtaposent dans une dégradation croissante d'imprécision qui éveille et excite l'imagination pour la conduire, sans lui faire violence, au terme final qui illumine et achève le sens de l'ensemble.

Une littérature née sous de tels auspices est fatalement vouée à se tenir éloignée du vulgaire, et à chercher son inspiration dans deux foyers seulement: l'ermitage et le château féodal. Mais, nulle part, un centre permanent ; dans l'ordre religieux, ni grand-prêtre, ni temple universellement tenu pour le Saint des Saints; dans l'ordre politique, pas d'unité, pas d'empire stable, pas de capitale durable. L'Inde n'a jamais eu de Jérusalem, de Delphes, d'Athènes, de Rome. Le travail de désintégration et de recomposition qui se poursuit sans arrêt dans l'ordre social paralyse tous les efforts de construction solide; si un chef de génie comme Chandragoupta le Maurya, ou comme Samoudragoupta, réussit à bâtir un empire, l'œuvre ne tarde pas à s'écrouler après lui. Les villes meurent comme les empires, sans laisser rien de plus qu'un nom sur le sol qui les a portées. En politique comme en religion, I'Inde est le pays de l'anarchie; il lui suffit d'avoir institué la hiérarchie dans l'ordre social, une hiérarchie toute spéciale, telle que l'Inde seule pouvait la produire et la tolérer : une hiérarchie d'aspect sévère et rigoureux, mais en réalité souple et ondoyante où l'esprit de conservation s'accommode et se concilie à merveille avec l'esprit d'innovation, où le respect le plus scrupuleux des formes sert surtout à dissimuler l'audace des changements. Le brahmane impose aux fidèles comme un dogme indiscutable l'autorité des Védas; l'autorité des Védas une fois admise, on est libre sans aucun scandale de professer l'athéisme absolu. Et l'adhésion est d'autant plus facile que les Védas n'ont jamais été constitués en canon; jamais un concile de brahmanes ne s'est réuni pour définir les textes authentiques et les textes apocryphes. Dans le personnel divin, même anarchie que dans le personnel religieux ; là aussi un travail continu de désintégration et de reconstitution. Dès les premières productions de la littérature indienne, les hymnes védiques, on rencontre cet état d'esprit, si singulier qu'il a déconcerté d'abord les interprètes occidentaux, habitués aux belles ordonnances des Panthéons classiques et du christianisme; chaque divinité est 
susceptible selon l'occurrence d'occuper le premier rang audessus de toutes les autres: ni monothéisme, ni polythéisme. Max Muller avait forgé un mot nouveau pour exprimer cette singularité : le mot kathénothéisme. Le même état d'esprit persiste dans l'Inde présente; chaque dieu, de quelque catégorie qu'il soit, est pour son fidèle le plus grand des dieux; il éclipse ou plutôt il absorbe tous les autres. Dans ce cas encore, les livres, qu'ils soient écrits dans l'Inde ou au dehors, offrent une simplification schématique: au sommet, les trois grands dieux, Brahma, Vishnou, Siva; au-dessous les dieux secondaires; plus bas encore, l'innombrable légion des dieux inférieurs. Mais Brahma, qui est censé occuper la première place, ne compte ni dans la religion, ni dans le culte ; il n'a pratiquement ni temple, ni dévots. Siva et Vishnou sont des raisons sociales ; ils se décomposent, clans la réalité, en une multitude de formes locales qui sont adorées comme autant de divinités différentes, considérées même parfois comme hostiles les unes aux autres. La doctrine des avatars, appliquée à Vishnou, et qui a permis à l'occasion d'assigner une place officielle au Bouddha dans le giron du Vishnouisme, est un effort heureux, mais restreint, pour introduire un peu d'ordre dans ce pullulement; mais Râma et Krishna, pour ne citer que ces deux avatars, diffèrent entre eux autant qu'ils diffèrent l'un et l'autre du Bouddha; un autre avatar, Parasou Roâma, «Râma à la hache » provoque à un combat singulier Râma, proprement Râmachandra «Râma-lune » qui est pourtant un avatar total du même dieu.

Née dans les ermitages au milieu des bois, ou dans les châteaux forts des princes féodaux, la littérature indienne en tire une double inspiration ; elle est méditative, ou elle est chevaleresque. La richesse et la vigueur des systèmes philosophiques atteste la puissance de la pensée indienne appliquée à la méditation, soit que dans le Védânta elle aboutisse à un idéalisme transcendant qui ne reconnaît d'existence véritable qu'à l'Être en soi, soit que dans le Sânkhya elle accepte le dualisme irréductible de la matière et de l'esprit et qu'elle essaie d'expliquer le développement du monde matériel par une sorte de chimie psychophysique, soit que dans le Vaiséshika elle ramène le monde de la qualité comme celui de la quantité à des combinaisons d'atomes doués de vertus diverses, soit que dans le Nyâya elle essaie de régler les démarches du raisonnement logique. Le langage est un phénomène d'ordre intérieur sur les confins de la physiologie et de la psychologie, et qui est aussi pour l'Hindou un phénomène 
d'ordre religieux ou sacré, puisque le sanscrit est tenu pour la langue des dieux et puisque les mots sanscrits, supposés en existence de toute éternité, sont les archétypes d'où la création procède; I'Inde sur e domaine aussi témoigne sa merveilleuse puissance d'introspection; elle crée la science le la grammaire et la porte de bonne heure un point qu'elle n'atteint nulle part ailleurs jusqu'aux temps modernes. Pour sa clientèle féodale, la littérature indienne a créé tout un monde de fictions, épopées, drames, contes, romans. L'épopée du Mahâ-Bhârata une véritable encyclopédie du parfait chevalier; elle a pour thème une simple guerre de clans entre deux branches de la même famille, les Pândava et les Kaurava qui se disputent I'hégémonie sur une petite bande de territoire aux environs de la ville actuelle de Delhi ; mais le poète a groupé autour de cet incident menu, que la légende avait déjà grossi jusqu'à y faire participer toutes les principautés de l'Inde, la somme de toutes les connaissances que doit posséder un bon seigneur féodal depuis l'art de combattre et l'art de gouverner jusqu'à la géographie; tant et si bien que l'épopée ne compte guère moins de deux cent mille vers. L'autre grande épopée, le Râmâyana, d'étendue plus modeste, se borne à chanter les exploits et les malheurs de Râma; jamais, il faut le proclamer à l'honneur de l'Inde, la littérature n'a peint un tableau plus touchant du dévouement conjugal et du dévouement fraternel. Le Râmâyana est, avec le drame de Kâlidâsa : Sakountalâ, avec le poème philosophique de la Bhagavad Gîtâ (simple épisode du Mâhâ-Bhârata, je le rappelle), une des rares œuvres vraiment humaines, largement humaines, que I'Inde ait produites. Pour le reste, quelle que soit la richesse prodigieuse de ses créations, quel que puisse être le talent et même le génie de tant d'auteurs indiens, la littérature indienne est et doit rester inaccessible au reste du monde, sauf un petit groupe de savants et de curieux. Les conceptions d'où elle procède, la société qu'elle dépeint, les conventions et les symboles dont elle vit sont trop spéciaux, trop particuliers à l'Inde pour qu'ils puissent jamais entrer dans le domaine commun de l'humanité.

Un humaniste, élevé dans les traditions classiques de l'Occident, est naturellement porté à condamner une pareille civilisation qui n'a pas su dépasser l'horizon de son pays natal, qui n'a jamais su s'élever à une vision universelle de l'homme et de la société humaine. Mais, avant de prononcer un jugement, il faut se rappeler dans quelles conditions la civilisation indienne est née, a grandi, s'est développée. Quelques poignées d'Aryens, 
apparentés aux Perses de I'Iran et aux ancêtres des Grecs, des Romains, des Celtes, des Germains, des Slaves, arrivent par la vallée de Caboul sur les bords de I'Indus, un millier d'années environ avant l'ère chrétienne ; ils portent avec eux le dépôt des institutions, des croyances, des techniques que la famille aryenne avait élaborées par un long effort ; ils trouvent devant eux un pays immense, occupé déjà par d'autres races, des races noires des Kolariens, des Dravidiens, qui vivent encore dans un état de demi-sauvagerie. Comment les nouveau-venus pourront-ils préserver la civilisation plus riche, plus noble, qui assure leur force et leur bonheur, et dont il se sentent responsables vis-à-vis de leurs descendants? Toute l'histoire de l'Inde, et jusqu'à notre époque, est l'histoire des efforts obstinément tentés pour résoudre ce problème. II faut rendre ce témoignage aux conquérants aryens qu'ils n'ont jamais essayé, autant que nous sachions, de supprimer la difficulté par l'anéantissement des races indigènes ; ils ont cherché des méthodes de collaboration susceptibles d'assurer à la fois leur propre sauvegarde et de laisser aux autres communautés le moyen de subsister. La formation des castes, hi hiérarchie des castes sont des moyens de défense contre l'absorption menaçante ; c'est un fait expressif que le nom des castes en sanscrit, varna, signifie exactement «la couleur ». L'Inde après tout n'est pas le seul pays qui ait eu l'horreur ou l'appréhension des noirs, des métis, des mulâtres. Depuis trois mille ans, I'Aryen poursuit dans I'Inde son œuvre de civilisation, et il est loin encore de l'avoir achevée. A cent milles de Calcutta, dans un paisible ermitage que les manguiers et les sâls abritent de leur ombre légère, Rabindranath Tagore, fleur du génie aryen, travaille à créer pour l'honneur de son pays une université libre où I'Orient et I'Occident doivent se rencontrer en vue de préparer une humanité meilleure; mais, tout à l'entour de l'ermitage, les Santals, les plus anciens aborigènes de l'Inde, continuent à vivre dans leurs villages primitifs, à parler leur langue antique, à pratiquer leurs coutumes immémoriales, à cultiver leurs rizières, comme si rien n'avait changé dans l'Inde depuis trois mille ans. Et partout, il en est encore de même.

Et ce n'est pas seulement contre la menace humaine que la civilisation indienne a dû et doit se défendre ; la nature est plus redoutable encore une chaleur qui déprime; une sécheresse qui grille le sol; une saison des pluies qui semble le déluge; des bêtes malfaisantes qui guettent l'homme sous ses pas, dans les broussailles, dans les arbres; des insectes plus malfaisants en- 
core qui ne s'attaquent pas seulement à l'homme, mais à ses biens, jusque dans son humble foyer. On voit quelle somme d'énergie il a fallu dépenser de générations en générations, pour que I'Inde ait produit cette magnifique floraison de doctrines, de religions, de poèmes, d'œuvres d'art, qui fait justement sa fierté et sa gloire. On comprend aussi que l'Inde ait donné au problème de la vie et de la destinée une solution originale, qui la sépare du reste du monde ; le reste du monde a médité, contemplé, observé sous des climats tempérés, où la nature restait à la mesure de I'homme; la civilisation de l'Inde, seule, s'est formée entre le Tropique et l'Équateur, en réaction contre une nature démesurée qui fait de la vie humaine un accident douloureux dans le pullulement infini de la vie universelle.

J'ai parlé de la civilisation indienne, considérée dans l'Inde même, comme si elle était identique au brahmanisme. J'ai laissé de côté le Bouddhisme, et à dessein. Le Bouddhisme, du point de vue intérieur de I'Inde, est un épisode secondaire ; I'Inde l'a désavoué depuis dix siècles; elle l'a même oublié jusqu'à en perdre le souvenir. Il a fallu le travail de la science occidentale pour apprendre à l'Inde moderne le nom du Bouddha et la grandeur de son œuvre. C'est au brahmanisme seul que l'Inde est restée constamment fidèle ; c'est à lui qu'elle s'est rattachée désespérément chaque fois que sa civilisation a paru être en danger. C'est en lui qu'elle s'est reconnue chaque fois, et qu'elle se reconnaît encore. On peut dire qu'il exprime le génie national de la civilisation indienne. Le bouddhisme exprime ce qu'il y avait en elle d'universellement humain; mais pour en assurer le triomphe, il a dû s'exiler de son berceau. 


\section{Civilisation bouddhique}

$\underline{\text { Retour au Sommaire }}$

Toutes les civilisations antiques ont le caractère commun de tenir pour identiques, indistinctes et indissolubles l'unité religieuse et l'unité nationale. Après une guerre heureuse, le vainqueur, qu'il soit Assyrien ou Romain par exemple, transporte dans sa propre cité la divinité propre du peuple vaincu; en absorbant cette divinité dans son panthéon, il absorbe pour ainsi dire la nationalité de son adversaire. Une religion est, comme un langage, le signe de ralliement où se reconnaissent les hommes du même groupe, et qui les oppose à l'étranger, quel que soit le groupe auquel il appartienne. Nulle part cette attitude ne se marque avec plus de rigueur que dans I'Inde. Pour les Aryas des temps védiques, les étrangers sont des Dasyou, des «brigands », des gens sans foi ni loi ; et aujourd'hui encore, dans l'Inde contemporaine sillonnée de chemins de fer et de lignes télégraphiques, l'étranger, de quelque origine et de quelque couleur qu'il soit, reste un Mleccha, « un homme qui balbutie », autrement dit « un barbare », car telle est la signification du mot que nous continuons nous-mêmes à employer après les Grecs. Tandis que les quatre castes de la société brahmanique sont nées respectivement, selon leur dignité, des membres du Pourousha, I'Homme mystique en qui le monde vit, ou de Brahma lui-même, les peuples étrangers que l'Inde voit passer à son horizon sont rapportés à des origines humiliantes. Le Râmâyana raconte que les Grecs (Yavana ou Yona) sont nés de la matrice (yoni) de Nandinî, la vache d'abondance que Visvâmitra voulait enlever à Vasishtha ; les Romains (Romaka) sont nés de ses poils (roma) ; les Scythes (Saka) sont nés de sa bouse (sakrt). Si les Grecs portent la tête rasée, ce qui est pour l'Hindou le symbole du servage, c'est qu'ils ont été vaincus autrefois par un ancêtre de Râma, Sagara, qui leur a infligé à perpétuité ce témoignage 
d'humiliation. Aucun pays ne semblait moins fait pour donner naissance, le premier, à une religion universelle ; rien n'est plus surprenant que de voir cet honneur lui appartenir.

La réalité historique d'un fondateur de religion est toujours difficile à atteindre ; elle l'est d'autant plus que le recul du temps rend l'histoire plus incertaine et la légende plus luxuriante. Nous connaissons Jésus moins bien que Mahomet, le Bouddha moins bien que Jésus. Une tradition constante, qui ne se heurte à aucune difficulté historique, fait naître le Bouddha sur l'extrême limite de la civilisation indienne, au pied même de l'Himalaya, à l'endroit où la jungle, les eaux stagnantes, les fauves et la malaria se coalisent pour fermer le passage des plaines du Gange aux montagnes. Il est de la famille des Sâkya, un nom étrange, il faut le reconnaître, inconnu à la tradition orthodoxe des épopées et des Purâna brahmaniques : on a depuis longtemps déjà voulu établir un rapport entre le nom des Sâkya et celui des Saka, l'appellation que les Hindous et les Iraniens ont étendue à tous les peuples scythiques; on a prétendu faire du Bouddha un nonAryen, un Touranien ; on a cherché dans les trente-deux caractères distinctifs et les quatre-vingts caractères secondaires de sa personne, tels que la tradition les énumère, des preuves de son origine touranienne. Prétention chimérique, puisqu'elle n'a aucune base positive, mais qui trahit bien le sentiment de surprise qu'on éprouve à rencontrer le fondateur du bouddhisme dans les cadres de la civilisation indienne. Il est le fils d'un seigneur; son père est le râja de Kapilavastou. Sa vocation, du point de vue de l'orthodoxie brahmanique, est donc le métier des armes; mais nous savons par des témoignages divers que la caste des guerriers, les kshatriya, refusait d'abandonner aux brahmanes le monopole de la spéculation et de l'enseignement philosophique. Janaka, le roi de Vidéha, voyait accourir autour de lui les auditeurs, avides de ses leçons; Ajâtasatrou, le sire de Kâsî (Bénarès), discutait en égal avec les plus savants brahmanes. Le fondateur de la religion Jaina, Mahâvîra, contemporain et rival du Bouddha, sortait, lui aussi, d'une famille princière. Après sa fuite du palais et son entrée dans la vie religieuse, le Bouddha va d'abord entendre les cours de deux maîtres instruits, Arâdakalâma et Roudrakapoutra ; plus tard, quand il a trouvé la voie et qu'il prêche sa doctrine, il lui faut lutter sans cesse contre les intrigues et contre les sophismes d'autres maîtres qui prétendent, eux aussi, résoudre l'énigme de la vie et ouvrir l'accès du salut. L'Inde autour de lui est en fermentation. On voudrait pou- 
voir préciser l'époque avec certitude. La tradition de l'église singhalaise, généralement acceptée en Occident, place le Nirvâna en 543 avant J.-C. ; mais beaucoup d'autres dates avaient cours dans d'autres écoles; en outre, il est incontestable que la tradition singhalaise nécessite une correction, car, admise telle quelle, elle donnerait au règne d'Asoka une date trop haute, en désaccord absolu avec les synchronismes sûrs dont nous disposons. On a donc proposé de ramener à 460, voire à 370 avant J.-C. la date du Nirvâna.

Quelle que doive être la solution définitive, le mouvement qui donne naissance dans l'Inde au bouddhisme et au jainisme est solidaire d'un mouvement plus étendu qu'on pourrait appeler la révolution mondiale du $\mathrm{vl}^{\mathrm{e}}$ siècle; le foyer le plus actif semble être l'Asie antérieure; les villes grecques de la côte asiatique voient surgir les premières écoles philosophiques: Thalès, Zénon, Héraclite; en Perse, Cyrus fonde le premier empire aryen qui couvre toute la partie occidentale du continent asiatique, des Pamirs à la mer Égée; Cambyse y ajoute l'Égypte ; Darius prend pied en Europe, et s'il n'arrive pas à conquérir la Grèce, il atteint I'Indus, installe ses satrapes en Gandhâra, sur la rive indienne du fleuve. Mais les armées perses sont les missionnaires d'une révolution religieuse: Zoroastre a enseigné aux Iraniens un culte épuré, dégagé des sacrifices sanglants qui souillent encore les autels de tous les peuples aryens. Si on voit surgir à la fois dans l'Inde le bouddhisme et le jainisme qui professent tous deux le respect complet de la vie et l'horreur du sang répandu, il est difficile de se refuser à y reconnaître un contre-coup de la révolution zoroastrienne en Iran, qui serait partie des frontières du monde indien, de Bactres, d'après la tradition iranienne. Mais du respect de la vie introduit dans le culte par Zoroastre, le Bouddha devait tirer des conséquences qui avaient échappé au saint de l'Iran : si la vie est respectable en soi, elle donne une valeur de respect à la personne qui la porte, indépendamment de son rang dans la société. Le Bouddha fonde une communauté ouverte à tous les hommes ; ou plutôt c'est mieux qu'une communauté telle que peuvent la constituer le maître et les disciples, le chef spirituel et ceux qui acceptent sa règle; c'est une famille; la désignation courante du moine dans les textes anciens, c'est Sâkyapoutra « le fils de Sâkya »; la pravrajyâ, l'acte initial par lequel il a « quitté la maison de famille » est un symbole clair ; le moine du Bouddha a changé de foyer ; il est entré par adoption et par choix dans une autre famille où il vivra au 
milieu d'une fraternité élargie. Mais la famille spirituelle a, elle aussi, un père qui anime toute la maison de son affection et de son amour. Le Bouddha tel que s'est plu à le peindre Asvaghosha dans ses beaux «Soûtra en forme littéraire » (Soûtrâlankâra) est humainement plus vrai que celui des vieilles traditions ; s'il a su se servir en maître accompli des ressources de la logique de son temps, s'il a su triompher les raisonnements de ses adversaires par une méthode familière et ingénieuse qui devance Socrate, il faut certainement chercher la cause profonde de son succès dans le prestige captivant de sa bonté universelle. C'est le rayonnement de cette bonté qui a encore animé les saints, les héros, les poètes, les artistes de l'église. Quand le Grand Véhicule est venu bouleverser la tradition étrécie des couvents, s'il a éclipsé la personne du Sage Sâkya, Sâkyamouni, derrière d'autres Bouddhas poussés brusquement au premier rang, il est cependant resté fidèle à l'inspiration initiale venue du Maître. Les Bodhisattvas, les candidats à la Bodhi, dans le monde réel ou dans les mondes imaginaires, sont par excellence « les fils des Bouddhas »; développant même la conception de la famille spirituelle que Sâkyamouni avait fondée, le Grand Véhicule donne aux Bouddha une «mère » qui est la Perfection de la Sapience, Prajnâ Pâramitâ. Et jusque dans les derniers siècles de l'église indienne, quand la décadence visible présage sa fin prochaine, la scolastique envahissante n'empêche pas des écrivains comme Sântideva, comme Sarvajnamitra, de trouver encore des accents de tendresse filiale, des appels à la pitié paternelle des Bouddhas, à la pitié maternelle de Târâ, qui sont assurés de trouver éternellement un écho dans les cœurs humains, mais qu'on chercherait en vain dans toute l'étendue de la littérature brahmanique. Avec le Bouddha s'est introduite dans la civilisation traditionnelle de l'Inde une tendance nouvelle qui en mine l'ensemble et en prépare la ruine. La civilisation brahmanique est une théocratie, une aristocratie, une anarchie systématisée dans des formes hiérarchiques; le bouddhisme n'a pour les dieux qu'une place de complaisance; il ne reconnaît pas les droits de la naissance dans l'ordre social ; il exclut de son domaine la société civile, sur laquelle il ne veut agir que par la contagion de l'exemple; il se borne à être une association religieuse, fondée sur la discipline et sur l'amour du Maître. L'histoire de I'Inde est désormais, jusqu'à la mort du bouddhisme indien, I'histoire de l'antagonisme qui oppose ces deux tendances d'où sont nées deux civilisations rivales. 
La mort du chef, qui marque souvent la crise suprême pour les religions nouvelles comme pour les nouveaux empires, ne compromet pas l'unité du bouddhisme naissant. Malgré des divergences dont la tradition orthodoxe n'a pu réussir à effacer entièrement le souvenir, le consentement de la majorité désigne, à chaque génération, une sorte de patriarche, qui ne doit pas ses pouvoirs à une procédure régulière, moins encore à une élection; il ne commande pas; ses avis mêmes n'ont rien d'impératif; on le vénère comme un modèle, mais on ne lui obéit pas comme à un maître. L'autorité souveraine n'appartient qu'à l'ensemble de la communauté, à ce qu'on pourrait appeler «la république des moines ». Elle s'exerce, dans les occasions solennelles, par délégation, par mandat, au moyen d'une assemblée représentative nommée sangîti, « concert » (comme nous parlons encore aujourd'hui du « concert des puissances») ; en Occident, on rend ce mot par le terme de « concile » emprunté à l'usage de l'église catholique; mais le Concile catholique suppose le pape comme chef de la chrétienté et une hiérarchie centralisée autour de lui. L'église bouddhique est une fédération de petites républiques, de monastères ou de groupes de monastères jaloux de leur autonomie. La tradition veut qu'un concile se soit réuni immédiatement après le Parinirvâna du Bouddha, à Râjagriha, pour fixer les textes canoniques, discours (soûtra) discipline (vinaya), philosophie (abhidharma), tels qu'ils étaient sortis de la bouche du Maître. Le fait, en tant qu'historique, est pour le moins douteux ; comme symbole, il est exact. Dès que le Maître a disparu, la Loi qu'il a proclamée exerce la souveraineté à sa place ; le cas est analogue, malgré des différences profondes, à celui de la Torah chez les Hébreux après Moïse ; la Loi prend la place du législateur, sans que l'autorité suprême ait à s'incarner dans la personne d'un chef.

La conversion d'Asoka au bouddhisme, vers le milieu du $\mathrm{II}^{\mathrm{e}}$ siècle avant l'ère chrétienne, place soudainement l'église en face de problèmes redoutables. A lire les nombreux écrits édifiants dont Asoka est le héros il semble que le grand empereur, maître souverain de I'Inde presque tout entière, ait mis humblement son autorité impériale au service de l'Église bouddhique; il finirait même par lui céder tous ses domaines. Mais nous connaissons l'Asoka réel, grâce à ses inscriptions gravées dans les régions les plus diverses de I'Inde; et l'Asoka réel, dans sa grandeur simple et dans la richesse de sa personnalité complexe, fait plus d'honneur au bouddhisme que le dévot humilié des fictions 
pieuses. Il a vraiment pénétré l'idéal bouddhique, et il le réalise en empereur. Le premier dans I'histoire de l'Inde, il publie ses édits par écrit, gravés sur des rochers. Sans aucun doute, il a emprunté l'idée aux empereurs Achéménides de la Perse dont l'influence se trahit partout sous son règne; il leur emprunte même le formulaire des inscriptions. Mais l'analogie de la forme n'en fait ressortir que plus vivement l'originalité du fond. Darius l'Achéménide avait dans ses inscriptions raconté ses aventures, ses exploits, ses conquêtes. Asoka ne se nomme même pas; il ne rappelle une de ses conquêtes que pour en déplorer les horreurs. Ses inscriptions sont des sermons, mais des sermons administratifs. II ne joue point au prédicateur religieux ; il a trouvé une doctrine qu'il croit bonne ; il ne veut pas l'imposer ; il espère la propager par la force morale du bon exemple; il confesse ses défaillances, ses efforts pour s'améliorer; il explique l'organisation qu'il a créée pour mettre ses fonctionnaires au service de son idéal. Un édit spécial recommande le respect de la vie chez les animaux; là encore il prétend payer d'exemple, il déclare supprimer de sa table les plats de gibier. Et ce n'est pas seulement aux dignitaires de l'État qu'il s'adresse, il veut atteindre le peuple. II se sert, dans chaque pays, d'un dialecte spécial, approprié à l'usage local ; admirable préoccupation, qui ne se retrouve plus chez aucun prince après lui.

Mais, s'il sert le bouddhisme, il entend bien aussi s'en servir. II a compris le parti qu'il peut tirer pour sa politique de cette doctrine largement humaine, qui ne s'arrête pas aux frontières d'un royaume ou d'une race. II inaugure la politique des missions religieuses; il envoie des apôtres en Syrie et plus loin encore à l'ouest, chez tous les héritiers de l'empire d'Alexandre ; il en envoie probablement aussi dans les pays au nord de l'Himalaya, et à Ceylan, et dans la presqu'île outre-Gange. II entend exercer un contrôle souverain sur la police intérieure et extérieure de l'Église; il porte des peines, au nom du pouvoir civil, contre les moines schismatiques; il fixe un choix de textes sacrés dont il recommande la lecture à l'usage des fidèles. D'après toutes les traditions, il convoque au nom de l'autorité civile, dans sa propre capitale, Pâtalipoutra, un concile pour régler des matières de dogme. Les mesures qu'il prend, en attestant son souci de régler un problème nouveau dans l'histoire du monde : les rapports entre l'Église et l'État, attestent aussi la puissance que l'église bouddhique avait atteinte sous son règne. En fait le bouddhisme était devenu une civilisation ; son idéal était sorti de l'enceinte 
des couvents pour se traduire sous des formes multiples. II avait créé une littérature, orale encore sans doute, rédigée certainement pour la plus grande partie dans une langue d'origine populaire, de la même famille que le sanscrit des brahmanes, un dialecte aryen du Magadha, voisin de la langue que le Bouddha luimême avait parlée; d'autres textes circulaient déjà, rédigés dans les dialectes divers des provinces où le bouddhisme avait pénétré. Des monuments splendides s'élevaient, qui transformaient en architecture le tertre primitif, stoûpa ou chaitya, qui avait longtemps servi à marquer les emplacements sacrés; autour du tertre, changé en coupole maçonnée, couronnée de la roue et du parasol, symboles l'un et l'autre de l'autorité souveraine qui appartenait à la Loi, se dressaient des balustrades, des portiques de pierre; l'art du sculpteur, employé auparavant à travailler seulement le bois, les décorait d'ornements, d'allégories, de scènes édifiantes tirées de la biographie du Maître ou des vieux fabliaux ingénieusement rattachés à ses existences antérieures. Des colonnes de pierre, érigées sur l'ordre d'Asoka lui-même, se substituaient aux anciens «poteaux de victoire » que les souverains d'autrefois avaient coutume d'élever ; elles marquaient les victoires de la Loi, les étapes des pèlerinages impériaux ; leur sommet s'ornait de chapiteaux élégants et d'animaux traités à la manière perse.

Les brahmanes épiaient avec inquiétude les progrès d'une civilisation rivale qui les surpassait ; jamais leur morgue aristocratique n'avait pensé à utiliser de pareils moyens de séduction pour agir sur la multitude. La fin d'Asoka, et la fin de sa dynastie qui suivit de près, marquent une réaction brahmanique qui paraît avoir pris un caractère violent. C'est du dehors que le bouddhisme allait reprendre de nouvelles forces et gagner des appuis pour une nouvelle ère de grandeur.

Sur la frontière nord-ouest de I'Inde, entre l'Empire des Séleucides en Syrie et l'empire des Mauryas, autour de Bactres comme capitale, un royaume grec indépendant s'était créé dès le temps d'Asoka; les rois de la Bactriane, Grecs d'origine, d'éducation, de langue, de culte, de civilisation, avaient admis à titre officiel la civilisation de l'Inde sur ce sol pourtant iranien d'histoire et de tradition ; Bactres passait pour le berceau de Zoroastre, et pourtant, sur les monnaies frappées par ces princes, si la face porte une légende grecque inscrite autour de la tête du roi, le revers porte une légende tracée en langue indienne dans 
un dialecte voisin du pali, et souvent au lieu des divinités grecques: Pallas, Héraklès, Nikè, etc., il présente des symboles indiens qui semblent être surtout des symboles bouddhiques: tels l'éléphant, l'arbre entouré d'une balustrade, etc. L'histoire de ces rois n'est guère, jusqu'ici, qu'une histoire numismatique. Mais un d'entre eux, Ménandre, nous est connu par d'autres témoignages, et ce que nous savons de lui nous laisse deviner ce que le bouddhisme doit à cette dynastie. Ménandre est le héros d'un ouvrage canonique du bouddhisme, qui nous est parvenu en deux langues ; en pali, c'est le Milindapanha, « les Questions de Milinda (roi des Grecs) » en chinois, c'est le Na-sien king «le soûtra de Nâgasena (le docteur bouddhique) ; le Na-sien king existe encore en deux recensions dans la collection chinoise du Tripitaka. L'original sanscrit est perdu, mais nous savons de source certaine qu'il a existé. La donnée de l'ouvrage est expressive : le roi Milinda est dans sa ville de Sâgala (probablement Sialkot, près d'Amritsar) au Penjab; il s'ennuie, il vient d'inspecter ses soldats, et en véritable Grec il voudrait s'exercer et se distraire à un passe-temps intelligent; et quel meilleur passe-temps pour un Grec que la discussion? «Ah, l'Inde est vide », s'écrie-t-il. Mais un docteur bouddhique de grande réputation, Nâgasena se présente ; il est prêt à soutenir une controverse sur les dogmes de sa religion. Le dialogue s'engage; les arguments s'affrontent; après un brillant tournoi, Milinda s'avoue vaincu ; il se convertit au bouddhisme, et il élève à Sâgala un couvent avec un temple pour commémorer sa conversion Nous apprenons de plus par les sources grecques, que à la mort du roi Ménandre, plusieurs cités se disputèrent ses cendres, comme on avait fait jadis pour les restes du Bouddha.

L'épisode de Ménandre montre en raccourci ce que le bouddhisme devait gagner au contact de la civilisation grecque; mis en présence d'étrangers intelligents, instruits, raffinés, exercés à toutes les subtilités de la dialectique, familiers avec des systèmes philosophiques de construction puissante, le bouddhisme, s'il prétendait les gagner à sa foi, devait réviser l'ensemble de ses dogmes et de ses thèses, enrichis et développés au caprice du hasard depuis le Nirvâna du Maître, afin de les organiser dans un ordre rigoureusement logique et cohérent. Ces étrangers, ils ne bornaient pas leurs exigences aux satisfactions de la raison ; pour eux, le vrai ne se séparait pas du beau; ils avaient donné à leurs dieux des formes plastiques voisines de la perfection; ils les avaient glorifiés dans des chefs-d'œuvre littéraires de tous 
genres. Le bouddhisme avait reculé jusque-là devant la représentation plastique du Maître, aveu d'impuissance ou marque de respect ; les textes qui s'étaient transmis visaient plus à instruire et à édifier qu'à provoquer l'admiration. L'exemple profita au bouddhisme ; il en tira des moyens d'action nouveaux.

Le royaume grec de Bactriane, après des jours glorieux où il avait atteint les rives du Gange, s'éteignit, vers le début du ${ }^{\text {er }}$ siècle avant l'ère chrétienne; épuisé par les rivalités intestines de généraux ambitieux qui se disputaient le pouvoir, il s'effondra devant l'invasion des Saka et des Koushana, venus des steppes du Nord. Le bouddhisme allait encore trouver des protecteurs dans ces étrangers à demi barbares, que le prestige des grandes civilisations éblouissait, et qui prenaient volontiers de toutes mains les dieux et les arts que la Grèce, l'Iran et l'Inde pouvaient leur offrir. Un des rois de la dynastie kouchane, Kanishka, joue un rôle décisif dans l'histoire du bouddhisme; maître d'un empire qui touche à la Chine, à la Perse, et qui absorbe toute I'Inde du nord, il semble s'appliquer à suivre l'exemple d'Asoka pour le surpasser. Mais cet autre Asoka est étranger à l'Inde ; ses images nous le montrent vêtu à la tartare, d'une tunique épaisse serrée à la taille, chaussé de hautes bottes; en travaillant avec succès servir la propagande du bouddhisme au dehors, il prépare la ruine du bouddhisme indien dans I'I nde. II convoque un Concile qui fixe en langue sanscrite le texte du canon sacré ; en adoptant la langue savante des brahmanes, le bouddhisme s'est isolé de la foule qui ne la comprend pas ; il perd en efficacité ce qu'il semble gagner en noblesse. Comme pour mieux marquer l'orientation nouvelle, le Concile porte son effort sur les textes de philosophie, il les complète, il les commente. Vers les territoires lointains qui n'ont pas encore entendu la Bonne Parole, des missionnaires s'élancent, protégés et servis par le prestige du souverain ; leur zèle ne connaît pas de frontières; ils passent en Asie Centrale, en Chine ; du côté de l'Occident leur trace se perd, mais leur œuvre n'est pas douteuse. La destinée ellemême amène spontanément au bouddhisme des prosélytes sur le sol indien ; la périodicité des moussons, longtemps ignorée du monde hellénique, est reconnue; un trafic régulier s'établit par mer entre les ports de la mer Rouge, du golfe Persique, et des côtes de I'Inde; des commerçants venus de l'Occident hellénisé (Yavana) s'installent au Kathiawar, au Guzerate ; ils adoptent le bouddhisme qui leur confère une sorte de droit de cité ; ils figurent parmi les donateurs de ces prodigieux sanctuaires creusés 
dans le roc au voisinage de la mer, à Karli, à Kanheri, etc On peut se demander si leurs conseils n'ont pas aidé ou présidé à la construction de ces merveilles qui évoquent les hypogées de l'Égypte et anticipent sur les cathédrales gothiques du Moyenâge.

L'influence des prosélytes étrangers se marque plus clairement encore dans la transformation des croyances. Au Petit Véhicule (Hînayâna), idéal de sainteté à l'usage des communautés monastiques, vient s'ajouter et bientôt se substituer le Grand Véhicule (Mahâyâna) idéal d'une Église militante qui prêche l'action, l'action désintéressée, mais l'action incessante. Des Bouddhas nouveaux, qui ne sont le bien propre d'aucun peuple élu, supplantent Sâkyamouni, fils de I'Inde ; des légions de Bodhisattvas également imaginaires se groupent autour d'eux. C'est ce bouddhisme transformé qui va conquérir l'Iran oriental, I'Asie centrale, la Chine, la Corée, le Japon, la presqu'île indo-chinoise et les grandes îles de l'archipel indien. Mais dans I'Inde, l'ère de gloire s'est fermée pour le bouddhisme; il n'aura plus d'Asoka, et quand les Huns viendront envahir le Penjab au vi ${ }^{\text {e }}$ siècle, l'église indienne ne retrouvera plus un Kanishka; elle verra se dresser un ennemi féroce, qui présagera déjà pour elle les jours sinistres de l'Islam. Et quand les Musulmans arrivent et dans une poussée impétueuse balaient tout le nord de l'Inde au cours du $\mathrm{XI}^{\mathrm{e}}$ siècle, le bouddhisme indien s'effondre, s'anéantit, sans le prestige même d'une agonie glorieuse.

II est surprenant qu'une grande religion puisse disparaître pour ainsi dire soudainement, et, dans son propre pays d'origine, et plus encore quand ce pays a l'immense étendue et l'infinie variété de I'Inde. On serait tenté d'incriminer le fanatisme destructeur de I'Islam ; mais le brahmanisme n'a pas été moins maltraité par les envahisseurs musulmans, depuis Mahmoud de Ghazni jusqu'au Mogol Aurang Zeb ; et pourtant il a survécu; à chaque épreuve, il a retrouvé des forces pour la surmonter et pour se redresser, aussi vivace que jamais. Le bouddhisme était, il est vrai, plus facilement vulnérable, justement parce qu'il était plus organisé ; il suffisait au Musulman de brûler et de raser les monastères pour suspendre, au moins temporairement, la vie entière de l'Église. Le Brahmanisme avait bien, lui aussi, ses communautés, ses couvents (matha), asiles de méditation et d'étude, gouvernés par des règles strictes de discipline ; mais le couvent, dans le brahmanisme, n'a jamais été qu'une institution secondai- 
re ; il peut disparaître sans grave inconvénient pour le culte et pour les fidèles. Dans le Bouddhisme, le couvent (vihâra, sanghârâma) est le foyer, le centre, le cœur, l'âme de la religion ; sans couvent il n'y a plus de moines; sans moines il n'y a plus de lien entre les fidèles et la Loi, sous quelque aspect qu'ils l'adorent: Bouddhas, Bodhisattvas, dieux, reliques, lieux saints, etc. Mais l'invasion musulmane n'a pas couvert toute l'Inde d'un seul coup; il ne lui a pas fallu moins de quatre ou cinq siècles pour pénétrer jusqu'au centre et jusqu'au sud de l'immense presqu'île; il ne manquait pas de retraites lointaines, de cantons isolés où des croyants énergiques, groupés autour de moines pieux, auraient pu tenter une résistance suprême, attendre des jours meilleurs, léguer à leurs descendants la tradition des siècles qui leur avait été confiée ; le cas a dû certainement se produire. En fait, nous voyons encore au $\mathrm{XIII}^{\mathrm{e}}$ siècle un prince de la région montagneuse des Sivalik, en plein Penjab, au milieu d'une contrée déjà submergée par le flot musulman, rester fidèle au bouddhisme, et même témoigner son zèle pieux par une offrande au temple de Bodhi-Gayâ, sur le site sacré entre tous où le Maître avait atteint l'Illumination et qui n'avait pas entièrement cessé d'attirer les pèlerins. Mais le cas est si rare qu'il serait difficile, dans l'état présent de nos connaissances, d'en citer un autre. La vie du bouddhisme indien s'est arrêtée totalement et définitivement aussitôt après les premières invasions des Musulmans, alors qu'à l'extrême nord et à l'extrême sud le Népal et Ceylan lui restaient fidèles, alors que toute l'Asie orientale, Tibet, Chine, Corée, Japon, Indochine, Insulinde continuaient d'adorer avec zèle les dieux et les saints que I'Inde bouddhique leur avait apportés.

Ce contraste même suggère, il semble, l'explication de l'énigme. Le bouddhisme, par le double jeu de ses forces internes et des événements historiques, avait de plus en plus perdu le caractère national qu'il tenait de ses origines pour prendre un aspect de plus en plus humain. Le développement du Grand Véhicule, en dissolvant la personnalité historique du Sage Sâkya, avait, consciemment ou non, rompu les dernières attaches entre le bouddhisme et le sol où il était né ; les nouveaux Bouddhas qui avaient passé au premier plan n'avaient pas d'histoire positive, n'avaient pas de géographie sacrée ; il n'y avait pas pour eux à situer une ville de la Nativité, comme Kapilavastou, ni une ville du Nirvâna, comme Kousinagara. Né comme un ordre monastique dans les cadres d'une société qui ne distinguait pas les 
croyances des institutions, le bouddhisme s'en était graduellement émancipé pour devenir une religion presque au sens moderne du mot, un système de dogmes et de pratiques qui visait à réunir les hommes dans une communauté indéfiniment élargie sans aucune préoccupation des formes sociales; il ne demandait à ses adeptes que de lui confier le soin et le contrôle de leurs rapports avec le transcendant et le sacré ; pour les contingences de l'ordre terrestre, il en laissait volontiers la charge à une autorité extérieure. Le succès de sa propagande tient en grande partie à ce trait original; il ne bouleverse pas les pays où il s'introduit ;il s'y insinue doucement, patiemment. Souvent le missionnaire se présente d'abord comme un médecin ; représentant d'une civilisation supérieure, il connaît des remèdes et aussi des charmes qui triomphent des maladies. II connaît aussi, et c'est là son arme la plus efficace, des histoires émouvantes qui font appel aux sentiments les plus profonds et les plus doux de l'âme humaine sous tous les climats et dans toutes les conditions : la douceur, la pitié, la tendresse, le dévouement; il dispose d'images pour illustrer son texte, sculptures ou peintures, productions d'un art consommé où le génie de l'Inde a été assisté par le génie de la Grèce et le génie de I'Iran. II gagne ainsi une clientèle qui le vénère, qui l'entretient; d'autres religieux viennent le rejoindre ; un couvent est fondé ; la vie régulière s'y établit qui sert de foyer et d'exemple. Le bouddhisme peut à bon droit réclamer l'honneur d'avoir conquis une partie du monde sans avoir jamais eu recours à la violence, sans avoir été jamais imposé par les armes. Il a connu la persécution, le martyre; ses adversaires l'ont accusé de saper l'ordre établi, en prônant la sainteté du célibat, en subordonnant les devoirs de famille aux devoirs religieux; on ne lui a jamais reproché de dresser une société nouvelle en opposition à la société établie. II aime, au contraire, à être soutenu par un appareil extérieur qui lui laisse le loisir de vaquer à sa besogne spirituelle; en Chine, c'est le Confucianisme qui lui a rendu ce service; au Cambodge, au Champa, à Java, à Sumatra, il a reçu l'assistance des religions brahmaniques, spécialement du Sivaisme.

En Indochine, en Insulinde, le voisinage des religions brahmaniques ne menaçait d'aucun danger l'existence du bouddhisme. Le Sivaisme, le Vishnouisme y étaient, comme le bouddhisme, des articles d'importation, étrangers au pays; les rois, la cour, la noblesse avaient pu les adopter, comme une culture élégante et raffinée ; ce n'était pas une civilisation qui avait pénétré 
jusqu'au plus profond des masses. La vie sociale continuait à s'y dérouler, sans préoccupation de Manou et des autres codes brahmaniques. Mais dans I'Inde il en allait autrement; le brahmanisme était solidaire de l'ordre social; il se confondait avec lui. A la différence du bouddhisme, qui avait opté pour un idéal d'humanité universelle, le brahmanisme était resté dans l'Inde exclusivement hindou; dans ce pays où se croisent tant de races, tant de langues, il était le seul symbole d'unité perceptible et reconnu par les multitudes. En présence de I'Islam, qui accourait le fer et la torche à la main, l'Inde d'un mouvement spontané et unanime se réfugia derrière la suprême barrière du brahmanisme. Sans doute I'Inde, au cours de sa longue et douloureuse histoire, avait souvent connu les invasions; mais jamais auparavant l'envahisseur n'avait pris figure d'apôtre, jamais le conquérant n'avait prétendu anéantir les dieux, les temples, les institutions du pays pour installer sur leurs ruines un dieu nouveau, un culte nouveau, une confrérie nouvelle qui semblaient imaginés à dessein pour heurter les traditions et choquer les consciences. La caste seule, telle que les brahmanes l'avaient réglée et maintenue, avec ses pouvoirs de contrôle et les sanctions dont elle disposait, était capable de faire échec à la propagande par la terreur que pratiquait I'I slam.

Pour rentrer au giron du brahmanisme, les fidèles du bouddhisme n'eurent certainement pas à faire un long chemin. Depuis des siècles, le bouddhisme dans l'Inde avait perdu l'inspiration qui l'avait animé au début; il avait cessé d'être une église pour devenir une école. Les récits des pèlerins chinois, et surtout de Hiouen-tsang, nous font illusion; nous n'avons rien à leur opposer du côté brahmanique; nous n'avons que par eux seuls la sensation de la vie réelle dans l'Inde, et nous nous laissons aller au charme, sans penser assez que nous avons affaire à des esprits prévenus, à des voyageurs dévotieux qui ne savent rien et ne veulent rien savoir en dehors de leur église, qui ne sont pas des explorateurs, mais des religieux, plus soucieux d'édifier que d'instruire. Ayons donc le courage de nous demander comment nous apparaîtrait le rôle du bouddhisme dans l'Inde depuis les Goupta ( $v^{\mathrm{e}}$ siècle), si nous devions nous borner, comme pour le brahmanisme et le jainisme, aux documents indiens, si nous ne disposions pas de Fa-hien, de Hiouen-tsang, de Yi-tsing. Nous considérerions alors le bouddhisme comme une des écoles philosophiques de l'Inde au même titre que le Védanta, ce « bouddhisme déguisé » comme il a été qualifié dans l'Inde même, ou le 
Sânkhya, par exemple. L'effort créateur de Dignâga et ses disciples en logique irait prendre sa place dans l'histoire du système Nyâya. La tragi-comédie du Nâgânanda nous apprendrait qu'un roi sivaïte comme Harsha Sîlâditya ne dédaignait pas d'emprunter un sujet dramatique aux légendes du bouddhisme. La grammaire de Chandragomin nous montrerait que le bouddhisme prétendait rivaliser avec les brahmanes eux-mêmes dans l'étude théorique de la langue sanscrite. Nous saurions par l'Avadânakalpalatâ de Kshemendra que, encore au début du $\mathrm{XI}^{\mathrm{e}}$ siècle, immédiatement après les incursions de Mahmoud le Ghaznévide, un brahmane cachemirien, adepte des Bhâgavata, pouvait s'amuser et amuser ses amis bouddhiques à tourner en vers malicieux un choix de récits édifiants tirés des livres sacrés du bouddhisme. II faut ajouter pour être juste que quelques œuvres comme le Bodhicharyâvatâra ou le Sragdharôstotra viendraient rappeler qu'un souffle d'émotion religieuse passait quelquefois encore dans la poésie bouddhique. Mais que pèserait ce témoignage en face de l'immense littérature des Tantra, qui dépasse en étendue tout l'ensemble de l'ancien canon, et qui combine dans un mélange inexprimable le mysticisme, la magie, la sorcellerie, l'érotisme, l'obscénité ? II faut le dire à la décharge du bouddhisme, la confusion est complète avec l'hindouisme brahmanique ; il ne subsiste du bouddhisme ancien, du bouddhisme authentique, que des noms et des mots vidés de leur sens. Arrivé à ce degré d'altération et de corruption, le bouddhisme n'avait rien d'utile à donner à l'Inde. Il a disparu parce qu'il avait perdu sa raison d'être. Son rôle historique, ce qu'on pourrait appeler sa mission humaine, avait été de servir de trait d'union entre l'Inde et les nations pour faire passer dans la circulation du monde les éléments de valeur universelle qui se trouvaient contenus dans le trésor jalousement gardé de la civilisation indienne. Tant qu'il eut l'occasion de remplir ce rôle, il se maintint actif et vigoureux; quand I'Inde commença à se replier sur elle-même, il perdit sa vitalité, s'alanguit, s'épuisa; quand I'Inde fut asservie par des étrangers hostiles, il périt. Grandi à la dignité de religion universelle, il n'a pas pu survivre dans sa patrie à une catastrophe qui l'isolait. Et c'est un signe des temps digne de la réflexion des penseurs, que de voir l'Inde d'aujourd'hui réagir contre un oubli millénaire, et revendiquer le Bouddha Sâkyamouni comme une de ses gloires, le bouddhisme comme une de ses traditions. 


\section{Orient et Occident}

\section{Essai sur l'humanisme}

Viresque Orientis et ultima secum

Bactra vehit...

(VIRGILE)

La cassure définitive entre l'Orient et l'Occident date de la Renaissance. Jusque-là, les deux groupes de civilisations se sentaient confusément en opposition réciproque; les luttes des Grecs et des Perses, la rivalité de Rome et de Carthage, la bataille d'Actium, le partage de l'Empire après Théodose, les Croisades révèlent tour à tour le conflit profond de deux masses humaines. Tantôt c'est la politique qui les divise, tantôt c'est la religion; mais les limites sont vagues, et l'ambition des conquérants peut aspirer à les abolir. Alexandre, élève d'Aristote, rêve et réalise presque une monarchie universelle; il absorbe dans la culture hellénique toutes les grandes civilisations du passé, AsieMineure, Syrie, Perse, Égypte et jusqu'à I'Inde même. Rome recueille l'héritage des lettres, des sciences, des arts helléniques et porte leur domaine jusqu'aux rives de l'Atlantique. Le christianisme, qui est à ses débuts une reprise de l'Orient sur l'Occident, se laisse bientôt gagner à l'idéal romain d'une domination universelle ; du Dieu des prophètes juifs, il veut faire le Seigneur de la terre entière. Le monde ancien est, après tout, si étroit qu'il se prête sans grand effort à une vision d'unité : l'Europe lui est fermée au delà du Rhin et du Danube, I'Asie au delà du Tigre et de l'Euphrate, l'Afrique au delà du Nil égyptien et de la lisière du Sahara ; plus loin, c'est le patrimoine des explorateurs, des marchands aventureux, et des conteurs inventifs. Le moyen-âge chrétien ajoute le Nord et le Centre de l'Europe. 
A partir de 1492, en cinquante années, le monde se double, se triple, se multiplie démesurément : un immense continent est découvert ; un autre, presque ignoré, est reconnu sur toutes ses côtes ; I'Inde, la Chine, le Japon entrent dans le mouvement régulier des échanges maritimes. Le premier voyage par mer autour du monde est accompli dès 1521. Tout est bousculé dans les rubriques courantes: des pays surgissent, et des hommes, et des dieux, et des langues, et des institutions que personne n'avait prévus. Rude épreuve pour les vieilles doctrines. Avec I'horizon du présent, la perspective du passé se transforme: sous la couche latine, on retrouve la Grèce; sous la couche chrétienne, la Judée. Tout ce qu'on avait cru dater d'un temps immémorial se rapproche, n'est plus qu'un héritage altéré des siècles plus anciens que le prestige d'une découverte toute fraîche embellit, ennoblit. Au regard de l'Église romaine, la vie du monde s'était développée sur le plan de l'Empire romain; de la cité romaine, que les empereurs avaient étendue jusqu'aux limites de ce qu'on croyait être l'univers, Saint Augustin avait fait la Cité de Dieu, gouvernée par les lois du Seigneur, conduite par sa sagesse d'étape en étape vers sa destination suprême, le triomphe définitif de la foi. C'est la vue que, au XvII ${ }^{\mathrm{e}}$ siècle encore, Bossuet, Père de l'Église, mais en retard sur son temps, développe en tableaux éblouissants dans son Discours sur ce qu'il ne craint pas d'appeler l'Histoire Universelle, quand les missionnaires mêmes de l'Église chrétienne ont déjà étudié et noté les traditions, légendaires ou positives, des Indes, du Tibet, de la Chine, du Japon. Cette mutilation volontaire, systématique, est un aveu : la vieille doctrine, construite pour un cadre restreint, ne s'ajuste pas au monde nouveau. Voltaire et Montesquieu lui opposent bientôt, avec une autorité victorieuse, l'Essai sur les Mœurs et l'Esprit des Lois qui couronnent et parachèvent l'effort laborieux d'émancipation poursuivi depuis deux siècles: I'homme est, en dehors des caprices de la métaphysique, un produit et un agent de l'histoire ; les sociétés et les institutions humaines sont l'œuvre du temps, du sol, du climat, et varient avec eux selon des relations nécessaires. L'homme est solidaire ainsi de tout le passé, de tout le présent, et solidairement responsable de tout l'avenir ; la destinée de chacun reste une tragédie métaphysique qui s'ouvre et se ferme sur un mystère; mais entre les deux énigmes qui l'étreignent à la naissance et à la mort, l'homme n'est plus totalement écrasé ; l'espace s'élargit un peu. La vie reste un point entre deux infinis d'ignorance; mais sur ces deux infinis l'intelligence a gagné du terrain. 
L'espèce humaine, qu'il prolonge et qui le prolongera, donne à I'homme une première raison d'être, qui ne résout rien dans l'ordre du transcendant, mais qui satisfait en quelque mesure les exigences les plus pressantes de la logique et de la raison. L'homme ne prend pas la place de Dieu; mais entre Dieu et lui I'humanité jette une sorte de pont qui dissimule l'horreur de l'abîme toujours béant aux deux extrémités. L'intelligence humaine, soulagée d'un long cauchemar de théologie, retrouve une fraîcheur nouvelle et s'abreuve avec délices aux flots souriants de la pensée grecque, qu'un heureux concours de catastrophes a détournés vers l'Europe. Pascal, au confluent de Montaigne et de Saint-Augustin, a su discerner d'un coup d'œil perspicace le trait essentiel de l'esprit nouveau qu'il incarne, en dépit de lui-même, tandis qu'il s'obstine désespérément à défendre l'esprit ancien ; dans son Fragment d'un Essai sur le Vide (ed. Havet, p. 592), il esquisse la doctrine en vertu de laquelle «toute la suite des hommes pendant le cours de tant de siècles doit être considérée comme un même homme qui subsiste toujours et qui apprend continuellement ». Les éditeurs de Pascal se sont plu à signaler des passages analogues chez Saint-Augustin, chez Roger Bacon, chez François Bacon, chez Descartes. Saint-Augustin avait, il est vrai, entrevu l'idée du progrès en constatant l'analogie du développement de l'homme et du genre humain, mais il s'était gardé de pousser plus loin ce parallèle. La Bible est l'interprète fidèle de l'antiquité tout entière quand elle place au berceau de l'homme « la naïve simplicité du monde naissant » suivie bientôt d'une déchéance plus ou moins irréparable. L'âge d'or n'est qu'au début; le présent est toujours l'âge de fer. Les espoirs messianiques proposés comme une consolation par Zoroastre, par l'Église bouddhique, par les Prophètes d'Israël ont toujours fini par être décidément trop lointains pour des religions en pleine activité ; si le Judaïsme et le Parsisme assoupis ont pu s'y arrêter, Bouddhisme et Christianisme les ont rapprochés à la portée des fidèles, pour les aider à franchir cette «vallée de larmes ».

Jusqu'à la Renaissance, l'Orient et l'Occident communient sous des espèces diverses, dans la même mystique, la mystique du salut. L'homme cherche et suit la voie qui, par les œuvres et par la foi, doit le conduire après la mort à l'éternité du bonheur, paradis des élus, absorption en Dieu, extinction totale. La Renaissance introduit une mystique nouvelle, la mystique du progrès. Une loi naturelle, garantie par l'expérience des siècles, 
veut que la suite des générations s'achemine d'étape en étape vers le bonheur idéal, et par conséquent réalise plus de vérité dans l'ordre de la science, plus de justice dans l'ordre de la société. La connaissance du passé prend dans cette mystique une valeur que I'histoire chez les Anciens n'avait jamais atteinte. Pour eux, I'histoire était surtout un cours de morale et une leçon de politique; elle perpétuait les grands exemples ou elle expliquait les destinées des états ; pour le reste, c'était une œuvre d'art ou une distraction de curieux. Avec I'humanisme, I'histoire devient la base même des sciences de l'homme. Elle est mieux et plus qu'une expérience; elle indique une direction, la seule dont I'homme dispose, puisque l'avenir reste inconnaissable. On s'explique alors la frénésie des savants à déchiffrer le passé. On recueille avec piété tous les monuments, tous les documents. Un Budé justifie sa gloire par un énorme in-folio De Asse, sur le sou romain. Les commentateurs, les lexicographes, un Casaubon, un Scaliger, un Saumaise égalent en renommée les écrivains, les artistes les plus fameux. La chronologie de la Bible, acceptée sans discussion, place la création à si courte distance que ce semble être un jeu d'atteindre aux origines humaines. Mais bientôt on s'achoppe, dans l'Extrême-Orient qui s'ouvre, à des civilisations qui sont réfractaires à l'ordre biblique. Un apocryphe indien, l'Ezour-Védam, est manié comme une arme de combat ; la date de Zoroastre se discute avec passion comme un problème capital. Les langues sacrées de l'Asie, le sanscrit, le zend, défendues avec une sorte de jalousie féroce par des prêtres que l'indiscrétion de l'Europe inquiète, sont acculées à livrer leur mystère. D'autres langues, plus récalcitrantes encore, paraissent inviolables sous le sceau d'un silence vingt fois, trente fois centenaire ; le génie d'un Champollion ne connaît pas d'obstacles, et recule d'un bond l'horizon du passé humain.

A de pareilles conquêtes, triomphe désintéressé de l'intelligence humaine sur l'ignorance, l'Orient n'a rien à opposer. En dehors des pays de la Renaissance, un Champollion ne s'est jamais rencontré, parce qu'il ne peut pas s'y rencontrer. Pour arriver à cette passion de la recherche, à cette soif de savoir, à cette volonté de découvrir, il faut une tradition continue, une philosophie vivante comme une force et devenue sûre comme un instinct. On croit volontiers, dans les cercles hostiles à l'Occident, qu'il suffit d'emprunter à l'Occident ses procédés techniques pour l'imiter, l'égaler, et rivaliser avec lui. C'est une erreur qui pèse aujourd'hui lourdement sur le monde. Les sciences occidentales 
sont solidaires de l'humanisme occidental; elles sont nées avec lui, elles ont grandi avec lui, elles sont inséparables de lui ; de part et d'autre, c'est la même attitude de l'esprit en face de questions d'ordre divers. La foi dans l'observation et dans l'expérience, qui soutient un Galilée ou un Pasteur, n'est pas un phénomène isolé qui se manifeste par hasard; elle procède d'un système de vie sociale qui la prépare et l'entretient; ni l'empirisme chinois, ni la rêverie hindoue, ni le fatalisme musulman n'ont chance de la susciter. La gravité de l'erreur orientale se marque surtout en politique; le malaise actuel du monde en est le fruit amer. L'Occident, héritier et disciple de la Grèce et de Rome, a élaboré au prix d'efforts douloureux et d'expériences chèrement acquises certains concepts et certaines formes appropriées à son long développement ; leurs noms, tantôt grecs, tantôt latins, décèlent la profondeur de leurs racines : patrie, nation, état, citoyen, aristocratie, démocratie, dictature. Aucun de ces mots n'a d'équivalent par ailleurs; il ne suffit pas, pour les rendre intégralement, de les transcrire ou de les traduire. Déjà, entre des civilisations voisines et apparentées, la simple traduction d'ouvrages littéraires pose des questions presque insolubles; jamais deux abstractions, dans l'ordre intellectuel ou dans l'ordre du sentiment, ne coïncident avec exactitude ; les mots les plus concrets eux-mêmes ne s'entourent pas du même cortège d'associations. La politique et la société se fondent sur un appareil d'abstractions des plus compliquées, et d'autant plus redoutables qu'elles réagissent en pratique sur toute la vie de tous les individus. Le vieil adage qui fait du traducteur un traître (traduttore traditore) n'a malheureusement pas cours en Orient; autrement les problèmes si difficiles que les empiètements occidentaux ont provoqués en Orient ne se poseraient pas dans des termes qui les rendent désespérés. On parle du nationalisme hindou sans penser que l'Inde n'a pas un seul mot indien pour désigner la nation; on part sur des équivoques, on aboutit à la confusion.

Si l'humanité dans son ensemble est solidaire, chaque groupe humain n'en est pas moins spécialement solidaire d'un type historique de civilisation. L'humanisme n'a rien à voir avec les rêves humanitaires où se complaît une sensibilité puérile; doctrine de faits et d'expérience, il se résigne à reconnaître la diversité des sociétés humaines; il tend, par des recherches poursuivies en tous sens, à en distinguer les traits propres pour aboutir à des définitions aussi complètes, aussi précises que la complexité des 
faits humains le permet. La crise de nationalisme qui agite l'Europe et qui par contagion s'étend au reste du monde, est son œuvre; quelque part qu'on l'étudie, on trouve au point de départ I'historien ou le linguiste. La renaissance des patois, la restauration des langues mortes sont les contrecoups inconscients des leçons de I'humanisme. L'ébranlement qui a suivi la Grande Guerre a secoué des léthargies millénaires; la Palestine du roi Salomon, l'Assyrie de Sémiramis ont revendiqué leurs droits à la vie nationale. D'honnêtes gens ont cru que la vertu magique du sol suffirait à ranimer les civilisations qui y avaient autrefois fleuri, sans tenir compte des changements survenus à l'entour. On aime à s'imaginer que chaque peuple crée spontanément sa culture propre, et qu'il la tire exclusivement de ses propres ressources; on oublie la part des voisins, qui jouent pourtant un rôle essentiel. Une civilisation est un moment précis de I'histoire universelle ; elle marque un point d'équilibre entre les forces internes d'un peuple et les forces d'influences qui s'exercent sur lui du dehors. Elle correspond à une carte de géographie politique, et elle est susceptible d'en suivre les variations. Une nation en plein épanouissement se trouve donc intéressée à la stabilité des états qui l'entourent. La longue persistance de la civilisation européenne tient peut-être en dernier ressort à la stabilité prolongée des états occidentaux; qu'un petit territoire comme l'Alsace-Lorraine puisse par ses fluctuations réagir sur la vie du monde entier montre à quel point de stabilité l'Europe occidentale est parvenue. Ici encore, la comparaison avec l'Orient est accablante pour lui : d'immenses espaces mal définis, mal différenciés, I'Inde, la Chine, I'Iran, le Turkestan, travaillés à de courts intervalles par des mouvements de croissance ou de décroissance démesurés, partagés entre des races diverses, étrangères et souvent hostiles l'une à l'autre. Les périodes de stabilité, toujours exceptionnelles, se traduisent aussitôt pour la civilisation en siècles glorieux : Mauryas et Gouptas dans I'Inde, Han, T'ang, Song, Ming, en Chine. Sans la rude poigne du pouvoir moscovite, instruit et équipé à l'européenne, l'Asie du Nord aurait connu récemment encore ces alternatives, qui lui furent jadis familières. L'Europe centrale, par l'amplitude de ses oscillations géographiques, participe de l'Asie plus que de l'Occident; le démembrement et la résurrection d'un état aussi vaste que la Pologne témoignent d'un stage encore bien flou de différenciations nationales. 
En fait, l'humanisme n'est pas l'Occident, l'Europe entière est loin de lui être acquise. Fondé sur l'étude d'une continuité de passé qui couvre à peu près trois millénaires, il est et il reste le bien propre des peuples qui ont effectivement participé à ce passé. On tend à croire, même chez nous, que l'étude du grec et du latin sont des jouissances de luxe, cultivées surtout pour des raisons de snobisme ou pour des raisons diaboliques de machiavélisme. Si cette opinion venait à dominer, toute la civilisation française serait mise en péril. Une faute grave de pédagogie a failli nous acculer à ce désastre irréparable. Tant que les études classiques ont prospéré sur le domaine même où la culture grecque et la culture latine avaient jadis fleuri, elles ont conservé leur sève vivace, elles se prolongeaient dans la vie quotidienne ; elles nourrissaient la pensée, alimentaient la réflexion; le présent communiait par elles avec le passé. Si la Muse de Ronsard avait « en français parlé grec et latin », elle n'en avait pas moins charmé un siècle d'intelligence et de goût; Boileau, qui lui adresse ce reproche, était, au dire de ses détracteurs « tout entier dans Horace ». De Sénèque et Lucain à Corneille, d'Euripide à Racine, d'Ésope à La Fontaine, de Théophraste à la Bruyère, le $\mathrm{XVII}^{\mathrm{e}}$ siècle sentait à peine le passage. Cent ans plus tard, dans la crise la plus profonde de la France, la Révolution est hantée de réminiscences classiques; Napoléon veut renouveler César, «Rome remplaçait Sparte ». Mais déjà la philologie a traversé le Rhin ; elle a mis le pied sur un sol resté inaccessible aux légions romaines; dans ces immenses espaces que Tacite au $1^{\text {er }}$ siècle décrivait encore comme on décrivait au $\mathrm{XIX}^{\mathrm{e}}$ siècle l'Afrique Centrale ou l'Australie, aucune tradition, aucun monument, aucun instinct héréditaire ne vient commenter les classiques. De I'I talie à I'I rlande, I'homme du peuple qui ne sait pas lire est imprégné de rappels, de souvenirs inconscients qui sont le legs des ancêtres oubliés, entretenus et rafraîchis par les clercs, par les lettrés; il reste le bénéficiaire des anciennes générations qui ont pensé, senti, organisé pour lui. Chez les « Germains », le grec et le latin sont l'apanage des docteurs, séparés de la multitude ; les livres sont des «textes » où la science allemande applique ses dons admirables d'érudition, de recherche, de construction systématique ; mais la vie secrète qui se dissimule dans les œuvres de l'esprit classique lui échappe ; elle les traite comme un matériel d'antiquités; dans ce travail elle excelle à tel point que son prestige s'impose aux nations de l'Occident. On l'imite, on la copie, on aspire à enchérir sur elle, et dans l'intervalle d'une génération, I'humanisme est frappé à mort. Le conflit philosophique 
qui oppose entre elles deux parties de l'Europe a éclaté dès la naissance de l'humanisme. Le vieil esprit de dogmatisme et de théologie a trouvé un refuge dans le mouvement religieux de la Réforme. L'Église romaine, héritière des méthodes de la Rome impériale, tendait à faire du pape l'empereur des âmes; vicaire de Dieu, il avait reçu sa délégation pour les administrer, et une hiérarchie savante lui permettait d'exercer son autorité spirituelle du haut du Saint-Siège sur les cantons les plus reculés. La société laïque, de plus en plus déchargée des problèmes transcendants, se détachait des mystères du ciel pour prendre pied solidement sur la terre. La création de la Société de Jésus, triomphante dès son berceau, consomme l'œuvre du christianisme romain ; le siècle a trouvé les directeurs complaisants auxquels il n'aspirait qu'à s'abandonner pour vaquer à des soins qui l'intéressent davantage. Mais la Réforme remet farouchement la conscience humaine aux prises avec Dieu, face à face, dans toute l'horreur de ce débat inégal; elle ressuscite pour chacun de ses fidèles la mystique absorbante du salut; elle ne lui laisse même pas le loisir de parier, comme l'admet le jansénisme mathématique de Pascal ; elle impose à son examen une foi, des croyances et elle le somme de s'y enfoncer. Elle est bien la réaction contre Rome, la Rome des papes, la Rome des empereurs, la Rome des arts et de la littérature. Les pays de vieille culture romaine ne s'y trompent pas; l'Italie, l'Espagne la combattent avec fureur ; la France, un moment surprise, se libère dans une explosion brutale, pactise encore un temps et brise le pacte dans une nouvelle crise de haine. Les rives du Rhin, les rives du Danube, où les colonies de soldats romains ont enfanté de grandes villes, gardent une fidélité inébranlable à Rome; I'Irlande, qui fut un des derniers foyers de la culture latine, reste catholique ; la Pologne, convertie à la culture latine en même temps qu'à la foi chrétienne, repousse la Réforme; l'Angleterre, tiraillée dans tout le cours de son histoire entre deux races et deux traditions qu'elle a réussi à fondre dans un type splendide de civilisation oscille longtemps, déchirée par des guerres civiles qui sont des guerres de religion. La Germanie, l'Europe du Nord qui lui est apparentée de langages et d'institutions, se détachent sans effort de l'Église romaine pour se donner avec ferveur à la Réforme.

Le conflit aujourd'hui change de forme et sous sa métamorphose gagne en acuité ; l'Europe et le monde entier derrière elle ont cette fois encore à choisir entre l'expérience positive et la 
mystique. Les théories de Rousseau, nées dans un des lieuxsaints de la Réforme, ont, d'étape en étape, abouti à Karl Marx ; la Réforme sociale a trouvé son Évangile et son Luther en Allemagne, et son Calvin en Russie. Le matérialisme historique abolit résolument une large portion de l'histoire humaine, que son dogmatisme condamne comme indigne. Une compagnie de Saints, en possession de vérités infaillibles, va ramener la nature humaine à sa pureté native ; l'âge messianique, l'âge d'or, tous les rêves qui ont réconforté la misère humaine, vont se réaliser. La guerre, la pauvreté, la haine, le mal seront détruits à jamais. L'Asie qui se retrouve dans ces mirages paradisiaques, les accepte comme des prophéties nouvelles; elle attend avec confiance le miracle qui fera fleurir sous ses yeux le manguier à peine planté. En face de ce dogmatisme séduisant, les vieux pays de I'humanisme glissent du doute salutaire au doute paralysant; ils sont déjà tout prêts à sacrifier le système d'éducation qui leur a donné la suprématie. Cet héritage du passé qu'ils ont longtemps revendiqué comme le titre authentique de leur noblesse, leur pèse maintenant comme un fardeau encombrant; ils aspirent à l'alléger, comme s'il dépendait d'eux de réduire l'histoire, tandis que l'histoire ouvre ironiquement devant eux des perspectives toujours plus lointaines. Voici que maintenant s'est créée la préhistoire, science au nom singulier et révélateur ; on avait naïvement cru toucher au seuil de la civilisation avec la chronologie de l'Égypte ou de l'Assyrie, et derrière elles des âges nouveaux se découvrent, l'âge du bronze, l'âge de la pierre, le néolithique, le paléolithique, qui donnent le vertige aux intelligences ancrées dans les vieux préjugés, mais qui semblent encore bien courts au regard des nombres astronomiques que l'infiniment grand et I'infiniment petit nous rendent aujourd'hui familiers. II faut que I'homme blanc, pour parler comme Kipling, accepte virilement son fardeau, ou qu'il cède la place. Plus l'histoire s'allonge, plus le prix de la civilisation s'accroît; quand on mesure la somme d'efforts qu'il a fallu pour aboutir au peu que nous sommes, au peu que nous savons, au peu que nous pouvons, on apprend les vertus suprêmes de l'homme : la patience et l'énergie; le pauvre roi de la nature retourne à sa place qui n'est ni si humble, ni si exaltée dans l'univers. Le progrès ne risque plus d'être pris pour une force aveugle ou pour une loi fatale ; il apparaît comme l'effort conscient, délibéré, obstiné d'une élite souvent payée de sa peine par le dédain, la persécution et le martyre. Une poignée d'individus a de tout temps mené le monde ; le reste n'a que réagi, par l'obéissance ou la résistance. Et l'effort de la société doit 
tendre à recruter cette élite nécessaire. Spiritus flat unde vult ; « l'esprit souffle d'où il veut souffler »; un choix plus large assure donc plus de chances; mais la vie pratique a ses exigences qui travaillent dans un sens opposé. On ne peut qu'admirer la bourgeoisie. française d'avoir cru avec tant de ferveur au grec et au latin ; Monsieur Jourdain a bravé le ridicule; il a pris des leçons de grammaire et de philosophie comme les grands seigneurs, et quand il s'est mis à leur place, il a su l'occuper. Grâce à tous ses Jourdains, la France a donné au XIX $x^{\mathrm{e}}$ siècle le spectacle unique d'une classe moyenne pénétrée tout entière par l'humanisme.

La perte de l'humanisme ne serait pas seulement la déchéance d'une classe, elle menace toute une civilisation. L'humanisme est une des rares forces qui combattent l'étroitesse des intérêts purement nationaux. Au temps des monarchies orgueilleuses et jalouses, il avait réussi à créer la première grande démocratie, la république des lettres, où tous les esprits cultivés pouvaient communier sans distinction de frontières, entre l'Atlantique, la Baltique et la Méditerranée. II a inspiré à la Révolution la Déclaration des droits de l'Homme et du Citoyen, magnifique utopie à ses origines, et qui pourtant a changé la face du monde; à la dignité morale de la personne humaine, proclamée avec une vigueur définitive par les classiques $d u \mathrm{XvII}^{\mathrm{e}}$ siècle, à la dignité intellectuelle de la personne humaine, affirmée par le $x \mathrm{VIII}^{\mathrm{e}}$ siècle, venait s'ajouter la dignité politique de la personne humaine, qui devait inévitablement conduire au suffrage universel ; la dignité sociale de la personne humaine est l'apport du $\mathrm{XIX}^{\mathrm{e}}$ siècle. Le problème s'est étendu ainsi des individus aux sociétés, et le $x x^{\mathrm{e}}$ siècle s'oriente résolument vers cette nouvelle phase. Des régions supérieures à l'individu, la recherche s'étend symétriquement aux régions inférieures de la conscience, du sous-conscient à l'inconscient. L'individu cesse d'être le miroir transparent où la pensée grecque avait appris à lire ; il est la somme obscure des hérédités léguées par un chiffre innombrable d'ascendants, il est le dépôt de sensations, d'impressions enfouies dans une ombre impénétrable d'où elles réagissent sans se laisser entrevoir. Ici encore se manifeste la différence caractéristique de l'Orient et de l'Occident. Les tenants du néo-bouddhisme, de la théosophie, et de tous les articles frelatés qui se réclament de la philosophie hindoue revendiquent bruyamment pour I'Inde I'honneur d'avoir donné naissance à ces conceptions. La transmigration des âmes et le karman sont à coup sûr de nobles hypothèses pour ratta- 
cher l'homme, par un lien de solidarité morale, au passé et à l'avenir ; ils découvrent dans l'individu actuel les résidus des actes antérieurs et l'amorce des destinées ultérieures; mais l'expérience sur laquelle ils prétendent se fonder est, à la manière orientale, une intuition réservée à une élite de voyants; elle échappe au contrôle et procède par affirmations dogmatiques ; jamais elle ne se fonde sur une expérience positive du passé, jamais elle ne contient une parcelle d'histoire ; il en est sorti une abondance prodigieuse de contes et de fictions qui sont peutêtre les chefs-d'œuvre de l'imagination et de la sensibilité humaines; I'histoire telle que l'humanisme la conçoit a d'autres ambitions ; elle subordonne à la raison tout le reste. Lequel vaut mieux ? La réponse finale est toujours un acte de foi ; mais sans la foi l'action est paralysée.

Et précisément la foi s'en va de l'Occident. Pour l'entretenir sans se départir de l'attitude critique que I'humanisme commande, il fallait un miracle de volonté, et le stimulant d'un succès éclatant. Mais après les triomphes prestigieux, la lutte se fait difficile. L'Occident a péché par orgueil ; et maintenant le bloc des haines, des rancunes, des jalousies s'est soudé ; il a trouvé pour l'animer une puissance installée au cœur de l'Europe, maîtresse de toutes les techniques, laborieuse, opiniâtre, qui porte dans la vie civile la rigueur de la discipline militaire, et qui, pour résoudre l'antinomie entre l'individu et la collectivité, a opté comme l'Orient pour la collectivité contre l'individu. Entre ces deux masses en équilibre instable, le Nouveau-Monde peut fixer le destin ; mais déchiré lui-même par la variété de ses origines, il oscille, ballotté entre les deux tendances, préoccupé avant tout de créer, à l'aide d'éléments hétéroclites, des nationalités nouvelles. Les voyageurs qui ont visité les écoles et les bibliothèques de l'Amérique n'ont pas manqué d'éprouver une admiration respectueuse devant le spectacle émouvant d'une société humaine surgie sur un sol où elle n'avait pas de racines et qui s'applique à dégager de sa courte existence les principes d'un idéal nouveau ; elle s'est donné avec une prodigalité magnifique des Universités nombreuses où les humanités, transplantées du vieux continent, poursuivent leur action bienfaisante en préparant une élite; mais à distance on ne veut voir que la profusion des instituts techniques, des écoles professionnelles, sans se rendre compte des conditions spéciales qu'impose la mise en valeur d'un pays neuf et surtout d'une société neuve, où, faute d'une culture suffisante, c'est la fortune qui classe les hommes. Entre les zéla- 
teurs et les détracteurs de ce qu'on appelle la culture matérielle ou utilitaire, l'humanisme est encore menacé par des adversaires insidieux; on propose de le restaurer sur des bases nouvelles, de substituer aux langues mortes l'étude des langues vivantes, riches déjà d'un long passé : le français, l'allemand, l'anglais, l'espagnol, l'italien, le russe ont en effet des littératures où l'intelligence et le goût peuvent se former ; elles ont drainé en grande partie le trésor des civilisations anciennes. Mais elles ont le tort de vivre, d'être des langues nationales, des instruments de propagande au service d'influences rivales; elles font partie du bagage nécessaire de I'homme cultivé ; un bon Européen se doit d'être d'abord un bon polyglotte ; on ne connaît pas la civilisation d'un pays tant qu'on n'en connaît pas la langue; en dehors des jouissances d'art que procure seule la lecture des originaux, la langue est le seul outil qui démonte le mécanisme intime de la pensée. Mais seules les littératures mortes ont atteint la sérénité qui n'appartient qu'aux choses d'outre-tombe; elles sont, pour emprunter la fameuse formule d'Aristote, purgées de leurs passions; elles sont le capital indivis de l'humanité ; elles ont cessé d'être nationales pour devenir humaines. Un Oriental qui veut s'initier aux civilisations de l'Europe n'a pas d'introduction plus sûre que le latin et le grec ; s'il s'en est rendu maître, le regard de sa pensée embrasse tout le domaine des idées communes à l'Occident; il en saisit l'unité profonde qui nous échappe trop souvent. On enseigne aujourd'hui le latin et le grec dans les Universités de l'Inde et du Japon ; il serait piquant, mais il serait douloureux de voir l'Occident déserter sa tradition quand l'Orient s'essaye à la lui emprunter. 


\section{Eastern humanism}

An address delivered in the University of Dacca.

on February $4^{\text {th }} 1922$

$\underline{\text { Retour au Sommaire }}$

II n'a pas semblé inutile de joindre aux Essais qui précèdent, cette conférence adressée à un public indien, qui reprend en grande partie les mêmes idées pour les rendre plus aisément accessibles à des esprits formés tout autrement que les nôtres; on a cru que la différence de mise au point pourrait intéresser et frapper le lecteur occidental. On a conservé la rédaction originale en langue anglaise, quelles qu'en puissent être les faiblesses, de préférence à une traduction, afin de rendre manifeste le caractère particulier de cet essai.

I beg first to thank my dear old friend, the Vice-Chancellor, for the happy opportunity he has afforded me of visiting Dacca and Dacca University. When he expressed to me the wish that I should deliver an address here, I was only too glad to comply with his request, hoping that I might in this way come into closer touch with you. I do not need certainly to remind you that Mr. Hartog has been all his life through chiefly interested in education ; wherever we have met since the happy days when we were both students in Paris University, we have discussed educational matters together; you will not be surprised if, happening to meet this time in India, and having to speak in the University which he is animating with such a masterly spirit, I have made up my mind to speak about a problem of education, that is Eastern Humanism.

Here I have connected two words which, I am afraid, meet for the first time. Humanism, though referring by its very name to the whole of mankind, is essentially Western; the thing as well as its denotation are of Western birth, and apply properly to the 
range of the Western mind. Humanism is, if I may say so, intellectual catholicity. The Catholic church, by the very strength of the name it has taken, implied the will to do away with local and national creeds and to build up a community which would embrace the whole extent of the world. Kath'olon is a Greek locution meaning as a whole'and may be conveniently defined as the term opposite to your Sanskrit pratyekam. You are probably aware of the fact that the Christian church has been built up on the ground and with the materials of the Roman Empire; its aim, conscious or unconscious, has been to pursue and to achieve on religious lines the magnificent work which the Roman power had been accomplishing on political lines. It is by no mere chance that we still speak of a "Roman Church" as well as of a "Roman Empire". Rome is still the seat as well as the symbol of a power which, though spiritual, ranks first among the ruling powers in the world. One of the Roman writers, an obscure officer who lived in the fourth century A. D., and who could attend the downfall of the Roman Empire, Rutilius Numatianus, has summed up in a line of genius the task which had just been completed by his beloved city: Urbem fecisti qui prius or bis erat "You have made into a city what was formerly the globe" - and as a long distant echo of the line and of the thought, the name of a new Pope has been this very week heralded from the Vatican to "the city and the globe", - "Urbi et orbi".

It may seem strange, and almost a contradiction in sense, that I should have called our Western humanism an intellectual Catholicity, since humanism came to birth at the time when the Church was splitting up, and when the Reformation was becoming a strong antagonist to the supremacy of Rome. But what I mean is that humanism is catholicity to the same extent that the Roman Church is the Roman Empire. Humanism inherited the tradition of the Roman Church in order to realise in the sphere of intellectuality what had successively been achieved in politics and in religion. After the downfall of the Roman Empire the intellectual unity of the Western world was broken for a long time. The Roman Empire, in its flourishing days, had absorbed the best of Greek cultures. One of the most famous Latin poets, Horace, an enthusiastic lover of his country, but thoroughly nourished on Greek models, has in beautiful lines acknowledged the debt of the Latin mind to the Greek genius: "Graecia capta ferum victorem cepit, et artes Intulit agresti Latio", "Captured Greece captured her fierce conqueror and brought her arts to 
Latin peasantry". But the partition of the Roman Empire, after the reign of Theodosius, cut asunder the unity of the Western world. Greece and Rome kept aloof, enemies to each other. Rome became a prey to Barbarians ; the Latin Church also was forced to spend all her efforts in converting wild invaders, and if manuscripts were still copied in some monasteries of higher rank, this painful annotation crept in, as an expressive symbol of degenerating knowledge: Graecum est, non legitur; "It is Greek, it cannot be read." Not only the language, not only the thoughts, but even the Greek characters had been forgotten.

But the loss was not a loss for ever; what had been injured and almost killed by the ruin of Rome came to be recovered by the ruin of Constantinople. Greek scholars, flying before Turkish conquerors, scattered and spread all over Western Europe, carrying with them their beloved text-books just when the West was longing for a new spirit of life, when the Western mind had got tired of dry servility to king and church, when selfexamination was asserting its rights against uncontested authority. And there was a large and beautiful literature, in which new ideals, and new aspirations could find sustenance, in which the most delicate shades of thought and feeling they were striving to utter had been described in words of eternity, described by men who had never known the Bible, had never known Christianity, by men who had been branded by the Church as heathens. After a long interval of centuries, the voice of the dead resounded again, coming as if from the grave, and new generations were wondering at its call, as though it had been an anticipation of their own. This was no artificial recovery, this was no scholarly restoration of a defaced past. It was re-birth, punarjanma, which is the exact equivalent of Renaissance. They had suddenly grown conscious of a new truth, which had escaped the merely religious faith, namely, the deep unity of human nature ; beneath all differences of creeds and countries, they had discovered a link which connected all human beings; after all, through crises and revolutions, and millenaries, Man was standing with the same unshaken features of love and hatred, joy and sorrow, hope and despair, pleasure and pain. This was the grand discovery which has inspired arts and letters since the first days of the Renaissance ; all proceed from humanism, and if you wish me to give you a clear definition of the word, I cannot do better than quote 
another Latin verse, written two centuries B. C. by a poet who used faithfully to follow Greek models ${ }^{1}$ : Homo sum, humani nihil a me alienum puto; "I am a man ; nothing human is, in my opinion, foreign to me". You may take that sentence as the common motto of Western civilisation. We do believe in the unity of mankind; we know, or we assume, that we belong to the whole of humanity and that the whole of humanity is connected with us; wherever a man lives, works, suffers, he is ours; we have to understand him, to clear away the casual differences which time and space may produce, in order to reach the permanent element of brotherhood which, we are sure, lies at the bottom of mind and heart. We consider mankind in the same way as India considered the individual man. India, both brahmanical and heretical, admits that every being is the temporary result of numberless former lives, gathering the inheritance of his own past from time immemorial, and that the present state of life may allow him, if well made use of, to improve his condition in times to come, even to reach in due time the highest stage of happiness, where sorrows and pains attached to individuality cease for ever. Our view of humanity partakes of the same conception ; for Western culture, mankind as a whole forms one collective body, in some respects analogous to the Purusha of the Rig-veda-sukta, whose limbs are sundry races and nations, which is evolving its own development through the efforts, harmoniously conibined, of all its parts; the chief aim of each human group is to become more and more conscious of the texture in which it is involved, in order to become more conscious of the part which is its own to play. In that light, the whole sequence of Western development in modern times appears as a continuous tenor of endeavour inspired by the same spirit, tending to the same goal: classical art first strives to delineate a universal scheme of beauty in lines, colours, and proportions; classical literature strives to delineate, in tragedy, in comedy, in epic, the common features of human characters, just as politics and economics strive to make out the dominant laws of human societies. The French Revolution, in proclaiming the rights of the man and of tile citizen, proved itself a legitimate offshoot of the Renaissance; Michael Angelo, Descartes, Molière, Rousseau, are all landmarks on the same road.

1 Terence 
History, when introduced into the range of humanism, ceases to appear as a mere collection of isolated facts, or as a simple matter of curiosity. It becomes a science, nay more, a method. In the distressing darkness through which mankind has to make its way, along the melancholy path where generations rise up only to fall dead after a few steps, history affords some clue to mark a direction; it gives some connected points of the curve, the ends of which nobody can approach. To get rid of the niass of ignorance which surrounds him, man has to extend more and more the range of his eyesight in time and in space; the dawn of Renaissance lights a way for Columbus to discover America ; the dawn of Oriental philology clears up the long riddle of Egyptian hieroglyph and of Assyrian cuneiform. It is a fact worthy of notice that the nations which were most efficient in the shaping of Western civilisation, the Greeks and the Hebrews, are among ancient nations probably the most accurate about history. Sometimes of their own will, still more under the pressure of events, both came to mingle with foreign powers and countries; both were equally keen in keeping records of the kings and peoples they had to deal with. The Hebrews, more gitfed on the religious side, wished to investigate the secret will of their God in the development of political events ; the Greeks, more intellectual, aimed at discovering, under the moving stream of human affairs, the permanent laws ruling the mind of man and the world of nature.

Now, after we have reached what we be neye to be lying at the bottom of Western culture, let us ask-has India anything to shew which may compare with Western humanism ? Of course, many are the sayings we may quote which seem to repeat or to anticipate the Latin verse of Terence ; I shall give only one instance : -

ayam nija : paro veti ganana laghucetasam udaracaritanam tu vasudhaiea kutumbakam.

"He is my own, he is a stranger ; this is the way light-minded people reckon ; but for the high-minded, the world is their family-home". If you take this passage alone, by itself, isolating it from the current of Indian thought, you may mistake it thoroughly. The writer of the stanza, whoever he may have been, Bhartrhari or any other moralist, has no concern with human culture; he is only dealing with ethics, and what he means is clear 
beyond any doubt. A man who is fully worthy of that name, satpurusha, does not allow himself to be fettered in bonds as narrow as relationship ; for his doings (that is exactly the purport of the Sanskrit caritanam) - the whole world is but a small house, a trifle in the endless extent of the universe. I i we try to translate his purport in Western words, one of the nearest approaches I may refer to is the often quoted sentence of Renan « Let us try to look at earthly things from the point of view of the star Sirius », that is far away enough not to be misled by small matters. And, by getting to the real significance of what had appeared at first as a striking analogy, we realise as an antithetic contrast the essential features of the Indian mind as compared with the Western mind. The ideal of Western culture, chiefly derived from Greek philosophy, is to form a citizen, a man able to realise his full power in the city, inside the city, for the best of the city as well as of himself. The Greek name for a 'city' is, as you probably know, polis, and you can see at a glance how much our whole life has been impregnated with that notion. We all speak of 'politics' and I suppose I need not explain to you what we mean by that word: but its proper meaning is 'things of the city'. Even if we speak of a man who pretends to keep himself above national, social, religious prejudices, we still denote him as a 'citizen of the world', cosmopolites, from kosmos, the world, and 'polités' a citizen. Flow typical is the difference if you compare the words of Bhartrhari as quoted above : vasudhaiea kutumbakam! For a Hindu, the family-house, kutumbaka, is the primary cell around which the whole world, as great as you may fancy it, centres; kinship is the only real bond you can not get rid of, but the best of men can extend it to the whole world. For a Westerner the city, which has since grown into nation, is the central body which freedom of mind does not suppress, but amplifies to the utmost. In translating the line of Bhartrhari I have rendered the word 'kutumbaka' by 'family-house', which is only a faint approximation, as it does not convey in itself the connotation of 'joint family' which is quite unknown in the West, and if I try to alter the Sanskrit text of Bhartrhari in order to force into it an expression of cosmopolitanism, I may repeat with him : ayam nija : paro veti ganana laghucetasam, udaracaritanam tu vasudhaiva... and here I have to stop suddenly. All the words up to the last, admitted of a double or an equivocal meaning, but no rendering of polis or, polites, occurs to my mind. Desa, svadesa, janapada are words which refer only to local outlines; rashtra, rajya, denote a common obedience to some higher and external 
authority which enforces law ; but how shall we express the City, the community of men submitted to laws established and enforced by themselves, bound by a common responsibility towards the same laws in the duty of maintaining and improving them, on the same piece of ground where their forefathers were living who originated them?

And here again we meet a capital contrast The striving for better laws, which brought on ceaseless revolutions in ancient Greece and which is still working in the West, proved an inducement to seek outside Greece for useful comparisons. Its most celebrated philosophers are reported as travelling through foreign countries before promulgating new laws, practical or ideal ; take, for instance, Pythagoras and Plato. Aristotle had collected over seventy city-constitutions in order to prepare his own work on Politics. The city, being a human institution, remains for ever open to changes for the better. But kinship, which we have found at the bottom of Indian life, is a natural fact, wrought either by God's will or the mechanism of karma, which does not admit of any change. A body of men living under the same authority, be it a king or an aristocracy, is only an accidental combination of groups, each of them being ruled by its own law, svadharma, another typical contrast with the Greek law, nomos, extending to the whole city. In such an order of things, a man who cared to go abroad and to compare would be an evil-minded person, to be strictly secluded from the community. We see the result. We have before us an enormous stock of old and mediæval Indian literature, Sanskrit and Prakrit ; we may read through thousands and lakhs of pages in search of information about foreign nations and countries all that we find amounts practically to nothing. Now we know from foreign sources to what an extent. India has been connected with all the great civilizations of the ancient world. Not to speak of Egypt and Assyria, Persia taught her Persia's own writing, her arts, her administration. Greek civilization had her colonies scattered all over the Punjab and along the Western coast. India herself sent her missionaries to Central Asia, to China, to Tibet, to Indo-China, to the Indian Archipelago, to East Africa ; it is only right to point out that India was one of the chief colonising nations in the past ; even in distant Japan, we can trace her living influence still expressed in the shaping of the alphabet; Palembang in South-Eastern Sumatra was the seat of a brilliant Hindu University; Cambodia and Java can still show monuments and inscriptions which 
should be the pride of Indian genius ; the island of Borneo, lying far off, has in her jungles some remains of Indian culture; the small island of Bali, east of Java, is still a Hindu microcosm, with a Sanskrit literature and law, and Indian gods. Arjuna was a popular hero with the Turks in the seventh century, as he still is with the Javanese, as Rama still is with the Cambodians. But the spreading of Indian civilization, which might have been for India a source of intellectual and social enrichment, proved in the end an impoverishment, if not exactly a failure, because it was never turned into an exchange. India sent for centuries many of her best men to carry far away her arts, her science, her philosophy, the magnificent productions of her creative genius; she brought nothing home as a compensation. People, even educated people, often try to make foreign invaders and conquerors responsible for the collapse of India ; I must honestly state that I do not believe they are right. India has had to pay for her unnatural aloofness. She had claimed to live apart, in a kind of sacred seclusion. But no nation can seclude herself from the common task of mankind. Conquerors came from outside, to enforce on her the duty of reciprocity which she boasted of escaping. I slam and Islamic invaders, at the cost of tremendous loss and ruin, brought her into the frame of a large community, the range of which extended from Morocco to China; then came European powers who entered the contest and won. Western culture was enforced on the Indian mind, as Persian and Arabic culture had been enforced on it in the past.

Thus, by the mysterious ways of Fate, India, though unwilling and even reluctant, has grown fit to become the home of an Eastern humanism, able to compete with our Western humanism. Nature and history seem to have consecrated her for this splendid work; she has the command of a vast ocean which divides her from the Cape and Australia, both within equally easy reach ; her overland ways had long brought her into communication with Persia, Turkestan, and China. The large majority of her vernaculars are cognate with the languages of Europe and America ; they make her a member of the Aryan family, not only by their vocabulary, but by the profound mechanism of thought which is implied in language. To her Aryan vocabulary she has added a large store of Persian and Arabic expressions which stand as a connecting link between her and the world of Islam. In the Far East she has already shown what she was able to do there. China, the China of Confucius and Lao-tze, was for a 
thousand years after Christ a field of Hindu activity ; China, in spite of her grudge against foreign influences, still bears the indelible stamp of Indian arts, morals and metaphysics. IndoChina and Indonesia proclaim by their very name the part India has played in their local civilizations. If the India of to day will awaken to a full consciousness of her destinies, if she is ready to respond to the call which is coming from West and East, the Universities of India will become the birth-place and the seat of a new Humanism, richer and brighter than the old Humanism of the West.

The work, indeed, is not a light one; it is a work of learning which can fructify by samadhi, the effort of self-concentration, a power which is essential to the Hindu mind; it must be an achievement of the spirit. Technical science is of no help here. Technical science has its utility in making life easier, in allowing men to enjoy more freely, more fully, the life of the mind; but it does not afford an aim to human life. Mind is the chief and must command. Long years before Christ, Buddha had already announced that supreme truth :

manopubbangama dhamma, manosettha, manomaya.

"Mind goes first in the world ; mind is the best ; mind is creative." Faithful to her old lines of tradition, India will never desist from her spiritual striving; she has learned from her owr experiences the dangers of splendid isolation; she will gladly associate herself with the 'joint-family' of humanity in their common search after truth, truth which is the only 'mukti-marga', the way to salvation. 